\title{
Influence of Core Auditory Cortical Areas on Acoustically Evoked Activity in Contralateral Primary Auditory Cortex
}

\author{
Andres Carrasco, ${ }^{1,2}$ Trecia A. Brown, ${ }^{1,2}$ Melanie A. Kok, ${ }^{1,2}$ Nicole Chabot, ${ }^{1,2}$ Andrej Kral, ${ }^{3}$ and Stephen G. Lomber ${ }^{1,2}$ \\ ${ }^{1}$ Brain and Mind Institute, Department of Physiology and Pharmacology, Schulich School of Medicine and Dentistry, University of Western Ontario, \\ London, Ontario N6A 5C1, Canada, ${ }^{2}$ Cerebral Systems Laboratory, Department of Psychology, University of Western Ontario, London, Ontario N6A 5C2, \\ Canada, and ${ }^{3}$ Laboratory of Auditory Neuroscience, Institute of Audioneurotechnology, Medical University Hannover, D-30625 Hannover, Germany
}

In contrast to numerous studies of transcallosal communication in visual and somatosensory cortices, the functional properties of interhemispheric connections between auditory cortical fields have not been widely scrutinized. Therefore, the purpose of the present investigation was to measure the magnitude and type (inhibitory/excitatory) of modulatory properties of core auditory fields on contralateral primary auditory cortex (A1) activity. We combined single-unit neuronal recordings with reversible cooling deactivation techniques to measure variations in contralateral A1 response levels during A1, anterior auditory field (AAF), or simultaneous A1 and AAF neuronal discharge suppression epochs in cat auditory cortex. Cortical activity was evoked by presentation of pure tones, noise bursts, and frequency-modulated (FM) sweeps before, during, and after cortical deactivation periods. Comparisons of neuronal response changes before and during neuronal silencing revealed three major findings. First, deactivation of A1 and AAF-induced significant peak response reductions in contralateral A1 activity during simple (tonal) and complex (noise bursts and FM sweeps) acoustic exposure. Second, decreases in A1 neuronal activity appear to be in agreement with anatomical laminar termination patterns emanating from contralateral auditory cortex fields. Third, modulatory properties of core auditory areas lack hemispheric lateralization. These findings demonstrate that during periods of acoustic exposure, callosal projections emanating from core auditory areas modulate A1 neuronal activity via excitatory inputs.

\section{Introduction}

Considerable work has been conducted to identify anatomical and functional properties of interhemispheric connections in the visual system (Choudhury et al., 1965; Hubel and Wiesel, 1967; Innocenti, 1980; Silveira et al., 1989; Yinon, 1994; Abel et al., 2000; Rochefort et al., 2007; Schmidt et al., 2010; Genç et al., 2011, for review, see Glickstein and Berlucchi, 2008). Specifically, transcallosal projections connecting visual cortical fields have been implicated in hemifield fusion (Choudhury et al., 1965; Hubel and Wiesel, 1967; Payne, 1990), midline receptive field extension (Antonini et al., 1979, 1983, 1985; Marzi et al., 1982), binocular activation (Berlucchi and Rizzolatti, 1968; Lepore and Guillemot, 1982; Blakemore et al., 1983; Payne et al., 1984), and depth perception (Gardner and Cynader, 1987). Collectively, these studies have greatly advanced our understanding of how we are able to perceive the visual world as a single percept.

\footnotetext{
Received April 12, 2012; revised Nov. 14, 2012; accepted Nov. 15, 2012.

Author contributions: A.C. and S.G.L. designed research; A.C., T.A.B., M.A.K., and N.C. performed research; A.C. analyzed data; A.C., T.A.B., A.K., and S.G.L. wrote the paper.

This work was supported by grants from the Canadian Institutes of Health Research, the Natural Sciences and Engineering Research Council of Canada, and the Canada Foundation for Innovation. We thank Pam Nixon and Amee McMillan for technical and surgical assistance during this study. Stereotaxic coordinates are provided using the Horsley and Clarke (1908) system as described by Reinoso-Suárez (1961).

Correspondence should be addressed to Stephen G. Lomber, Cerebral Systems Laboratory, Department of Physiology and Pharmacology, M216 Medical Sciences Building, University of Western Ontario, London, ON N6A 5C1, Canada. E-mail: steve.lomber@uwo.ca.

DOI:10.1523/JNEUROSCI.1784-12.2013

Copyright $\odot 2013$ the authors $\quad 0270-6474 / 13 / 330776-14 \$ 15.00 / 0$
}

In auditory cortex, functional investigations of ipsilateral corticocortical communication have provided evidence of modulatory effects between core and higher order auditory cortical fields (Rauschecker et al., 1997; Carrasco and Lomber, 2009a, b, 2010). Despite the valuable information demonstrated in these studies, to date, the extent, type, and specificity of interhemispheric communication across auditory cortical fields remains vague (Mitani and Shimokouchi, 1985; Kitzes and Doherty, 1994). The conspicuous lack of functional research investigating transcallosal communication in the auditory system is contrasted by well accepted anatomical models of interhemispheric projections across auditory cortical regions (Diamond et al., 1968; Imig and Brugge, 1978; Code and Winer, 1985; Rüttgers et al., 1990; Rouiller et al., 1991; Morel et al., 1993; Lee and Winer, 2008a). Central to the present study are neuroanatomical tracing investigations showing that, in the cat, afferent transcallosal projections to primary auditory cortex (A1) emerge predominantly from contralateral A1 (>50\%) and the anterior auditory field (AAF; 10 to $<50 \%$ ) (Lee and Winer, 2008a). Based on these neuroanatomical reports, the present study examines functional characteristics of interhemispheric projections between core auditory areas.

Founded upon models of common information processing across sensory systems (Olshausen and Field, 2004), reports of neuronal response strength decreases in primary cortical fields [visual (Payne et al., 1991); somatosensory (Clarey et al., 1996)] during deactivation of contralateral homologous regions, and known interhemispheric connections in the auditory system (Lee and Winer, 2008a), we hypothesized decreases in response strength of contralateral auditory cortex neurons during sup- 
A
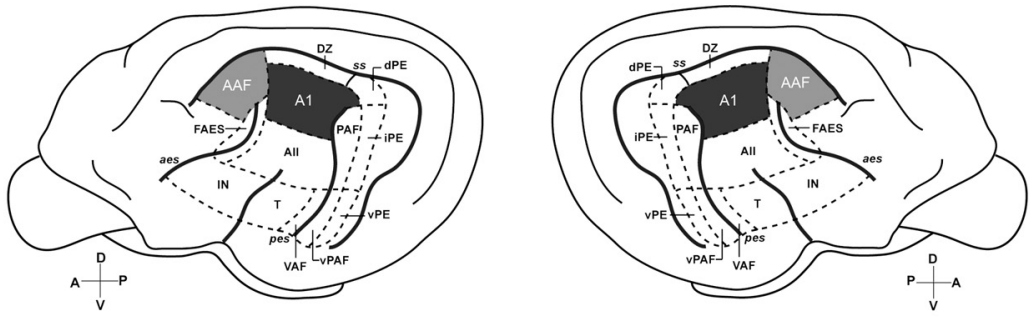

B
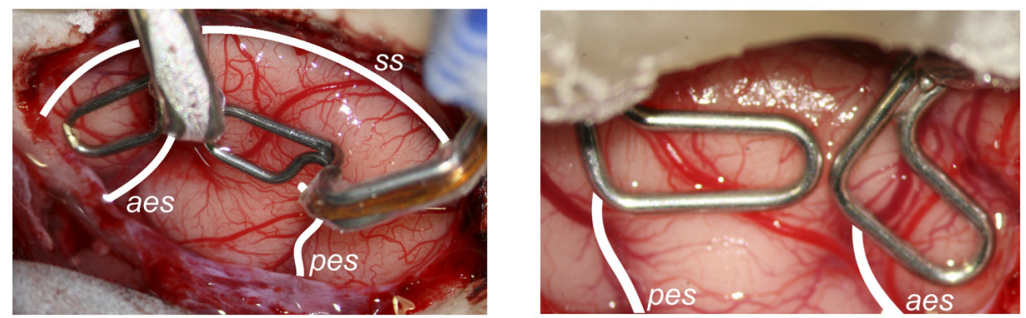

C

D
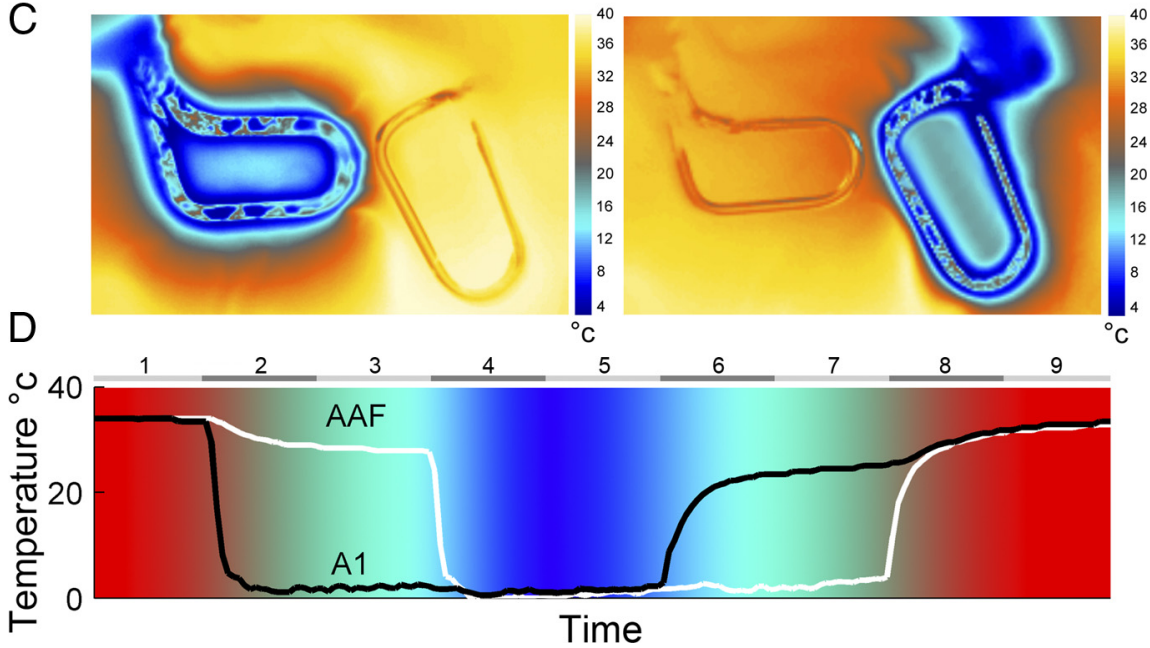

Figure 1. A, Schematic illustration of the left and right hemispheres of the cat cerebrum showing the 13 areas of cat auditory cortex. A1 is highlighted in black and AAF is shown in gray. $\boldsymbol{B}$, Representative examples of reversible cooling loop placement in left (left side) and right (right side) hemispheres from two implanted animals. temperature changes during A1 (left) and AAF (right) cooling deactivation epochs. $\boldsymbol{C}$, Temperature changes were recorded from a single animal during cooling loop. Notice that deactivation did not extend to adjacent cortical fields. D, Temperature changes recorded at A1 and AAF cooling loops of an implanted animal during a complete cooling deactivation cycle. Numbers on top indicate the phase of the cycle, with even numbers representing transitional temperature periods and odd numbers showing constant temperature epochs. Note that colors are presented as a guide of cortical temperature changes during cooling deactivation and are not associated with a color bar. A1, primary auditory cortex; All, second auditory cortex; AAF, anterior auditory field; $\mathrm{dPE}$, dorsal posterior ectosylvian area; DZ, dorsal zone of auditory cortex; FAES, auditory field of the anterior ectosylvian sulcus; IN, insular region; iPE, intermediate posterior ectosylvian area; PAF, posterior auditory field; $T$, temporal region; VAF, ventral auditory field; $v P A F$, ventral posterior auditory field; $v P E$, ventral posterior ectosylvian area. The sulci are indicated by italics: aes, anterior ectosylvian sulcus; Ss, suprasylvian sulcus; pes, posterior ectosylvian sulcus. D, dorsal; $A$, anterior; $P$, posterior; $V$, ventral.

pression of callosal afferent activity. The hypothesis was tested by examining the impact of individual and combined $\mathrm{Al}$ and $\mathrm{AAF}$ reversible deactivation on contralateral A1 neuronal response activity in the cat. Statistical analyses revealed decreases in activity across A1 laminae during silencing of contralateral core auditory cortical fields. These findings demonstrate that during acoustic exposure, callosal projections emanating from core auditory areas regulate A1 neuronal responses via excitatory inputs.

\section{Materials and Methods}

Overview. Neuronal responses to acoustic signals were measured in the right (two males and two females) and left (one male and two females) primary auditory cortices of seven adult $(>6 \mathrm{M})$ domestic cats (Felis catus) (Fig. 1A). Procedures were conducted in accord with the National
Research Council's Guidelines for the Care and Use of Mammals in Neuroscience and Behavioral Research (2003), the Canadian Council on Animal Care's Guide to the Care and Use of Experimental Animals (Olfert et al., 1993) and were sanctioned by the University of Western Ontario Animal Use Subcommittee of the University Council on Animal Care. Detailed descriptions of methodological procedures have been published (Carrasco and Lomber, 2009b, 2011).

Cooling loop and head holder implantation procedures. Approximately 2 weeks before electrophysiological recording, each animal was unilaterally implanted with A1 and AAF cryoloops over the right or left hemisphere (Lomber et al., 1999; Lomber, 1999). Probes of various sizes and shapes were fabricated by shaping loops of 23 gauge stainless steel hypodermic tubing (Lomber et al., 1999). Before surgery, cryoloops were sterilized with ethylene oxide gas. During the $24 \mathrm{~h}$ period before cryoloop implantation, cats were fasted and given dexamethasone $(1.0 \mathrm{mg} / \mathrm{kg}, \mathrm{i} . \mathrm{m}$.). Cannulation of the cephalic vein permitted administration of anesthetic and infusion of fluids (2.5\% dextrose and half-strength lactated Ringer's solution). Sodium pentobarbital ( $\sim 25$ $\mathrm{mg} / \mathrm{kg}$ to effect) was administered intravenously to induce general anesthesia. Animals were then placed in a stereotaxic frame (David Kopf Instruments, model 1530) and prepared for surgery using procedures described previously (Lomber et al. 1999). A midline incision was made in the scalp and the temporalis muscles were detached medially and reflected laterally. Craniotomies were made over auditory cortex and the dura was incised and reflected to expose the cerebrum. Location of cortical fields implanted was determined based on anatomical markers (Reale and Imig, 1980; Imaizumi et al., 2004; Carrasco and Lomber, 2009b) (Fig. $1 B)$. A1 cryoloops were $\sim 6 \mathrm{~mm}$ long and extended lengthwise across the middle ectosylvian gyrus, between the dorsal tips of the anterior and posterior ectosylvian sulci (approximately A4-A10 ${ }^{1}$; Reale and Imig 1980; Fig. 1). AAF (Knight 1977; Reale and Imig 1980; Phillips and Irvine 1982) cryoloops were $\sim 6 \mathrm{~mm}$ long and were located on the crown of the anterior suprasylvian gyrus between approximately A11 and A17. Appropriate size and shape cryoloops were selected based on cortical topography and field size during implantation procedures (Fig. 1B). In four animals, after cryoloop placement and before incision closure, cortical cooling was induced by pumping chilled methanol through the lumen of the cryoloops and thermal images were acquired to determine the extent of cortical temperature changes (FLIR; model SC325) (Fig. 1C). Copper/ constantin micro-thermistors were attached to the union of cryoloops to monitor probe temperature.

Following cryoloop placement, the dura was repositioned or Gelfilm was placed over the exposed cerebrum. With exception of where the cooling tubes exited the skull, the previously removed bone piece was replaced. Skull screws and dental acrylic were applied to secure the cooling loop and bone pieces. Finally, a head holder was attached to the frontal bone using skull screws and dental acrylic. The head holder permitted the animal to be held in the stereotaxic frame during electrophysiological recording without use of ear bars, which allowed the auditory 
canal to receive unobstructed presentation of acoustic signals. Dermal incisions were closed with 3-0 silk sutures that were removed 7-10 d later. Buprenorphine analgesic $(0.01 \mathrm{mg} / \mathrm{kg}$, i.m. $)$ was administered during the first $72 \mathrm{~h}$ after awakening. Decreasing doses of dexamethasone were administered over the next week, and fluids $(2.5 \%$ dextrose and halfstrength lactated Ringer's solution, $20 \mathrm{ml} / \mathrm{kg}$, s.c.) were infused as needed. The cats also received systemic antibiotics for 1 week to guard against infection. In all cases, postsurgical recovery was uneventful.

Surgical preparation for electrophysiological recording. On the day before the commencement of electrophysiological recordings, animals were anesthetized with ketamine $(20 \mathrm{mg} / \mathrm{kg}$, i.m.), the cephalic vein was cannulated with an indwelling catheter, and dexamethasone $(1.0 \mathrm{mg} / \mathrm{kg}$, i.v.) was administered to reduce the likelihood of edema during surgical procedures. Animals were fasted overnight. The following day, an initial dose of sodium pentobarbital ( $25 \mathrm{mg} / \mathrm{kg}$, i.v) (Cheung et al., 2001) was used to induce a deep state of anesthesia. Dexamethasone $(1.0 \mathrm{mg} / \mathrm{kg}$, i.v.) and atropine $(0.03 \mathrm{mg} / \mathrm{kg}$, s.c.) were administered to reduce the risk of brain inflammation and respiratory secretions, respectively. The larynx was anesthetized (Cetacaine; Cetylite Laboratories) and the trachea was intubated. Supplemental doses of sodium pentobarbital were administered as needed to maintain a state of areflexia. Electrocardiogram and blood oxygenation were monitored. Body temperature was maintained at $37^{\circ} \mathrm{C}$ with a water-filled heating pad (Gaymar, model T/pump). Hydration was achieved via an infusion pump (2.5\% dextrose/halfstrength lactated Ringer's solution, $4 \mathrm{ml} \mathrm{kg}^{-1} \mathrm{~h}^{-1}$, i.v.). The animal was held in the stereotaxic frame with the head holder implanted in the procedure detailed above. A craniotomy was made over areas A1 and AAF, contralateral to the implanted hemisphere. The dura was resected, silicone oil was applied to the exposed tissue to prevent desiccation, and a digital picture was taken to maintain a record of microelectrode recording locations.

Stimulus generation and presentation. Electrophysiological recordings were completed on a vibration-free table (Technical Manufacturing Corporation, model 63-500), inside an electrically shielded double-walled sound chamber. Acoustic signals were digitally generated with a 24-bit $\mathrm{D} / \mathrm{A}$ converter at $156 \mathrm{kHz}$ (Tucker-Davis Technologies, model RX6), and delivered in the free-field (Tucker-DavisTechnologies, model FF1) positioned $15 \mathrm{~cm}$ from the center of the head and contralateral to the recording hemisphere. Signals were calibrated with a $1 / 4$ inch microphone (Brüel and Kjær, model 4939). Features of acoustic signals used in the present investigation have been described (Carrasco and Lomber, 2011). In brief, three types of acoustic signals were used. (1) Pure tones varying in frequency $(250-64,000 \mathrm{~Hz}$ in $1 / 16$ octave steps) and amplitude (0 to $75 \mathrm{db}$ SPL in $5 \mathrm{~dB}$ steps) were presented in pseudorandom order $(25 \mathrm{~ms}$ long, $5 \mathrm{~ms}$ rise and fall times, cosine squared gated) at a rate of $2 \mathrm{~Hz}$. A1 neuronal responses to 2064 frequency-intensity combinations were used to generate peristimulus time histograms (PSTHs) during each cooling condition. Frequency-intensity combinations were delivered once per cooling phase. (2) Twenty-five milliseconds long white noise bursts composed of frequencies ranging from $1-32 \mathrm{kHz}$ ( $5 \mathrm{~ms}$ rise and fall times, cosine squared gated) were presented 600 times per cooling phase at a rate of $2 \mathrm{~Hz}$. (3) Logarithmic frequency modulated (FM) sweeps starting at $1 \mathrm{kHz}, 2 \mathrm{kHz}, 4 \mathrm{kHz}, 8 \mathrm{kHz}, 16 \mathrm{kHz}$, or $32 \mathrm{kHz}$ and moving either up or down from 1 to 5 octaves were presented. Regardless of spectral-frequency distance, each FM sweep was $250 \mathrm{~ms}$ in duration. Each range-direction combination was presented 50 times per cooling phase at $2 \mathrm{~Hz}$. Apart from pure tones, signals were calibrated and delivered at $65 \mathrm{~dB}$ SPL.

Reversible cooling deactivation. The cooling method to reversibly deactivate neural tissue is a potent and appropriate technique for examining cerebral interconnections and has a number of highly beneficial and practical features (Lomber, 1999). First, limited regions of the cerebral cortex can be selectively and reversibly deactivated in a controlled and reproducible way. Baseline and experimental measures can be made within minutes of each other (Lomber et al., 1996). Second, repeated cooling induces neither local nor distant degenerations that might compromise conclusions (Yang et al., 2006). Third, as the major effect of cooling is to block synaptic transmission, activity in fibers of passage is not compromised (Jasper et al., 1970; Bénita and Condé, 1972). Overall,
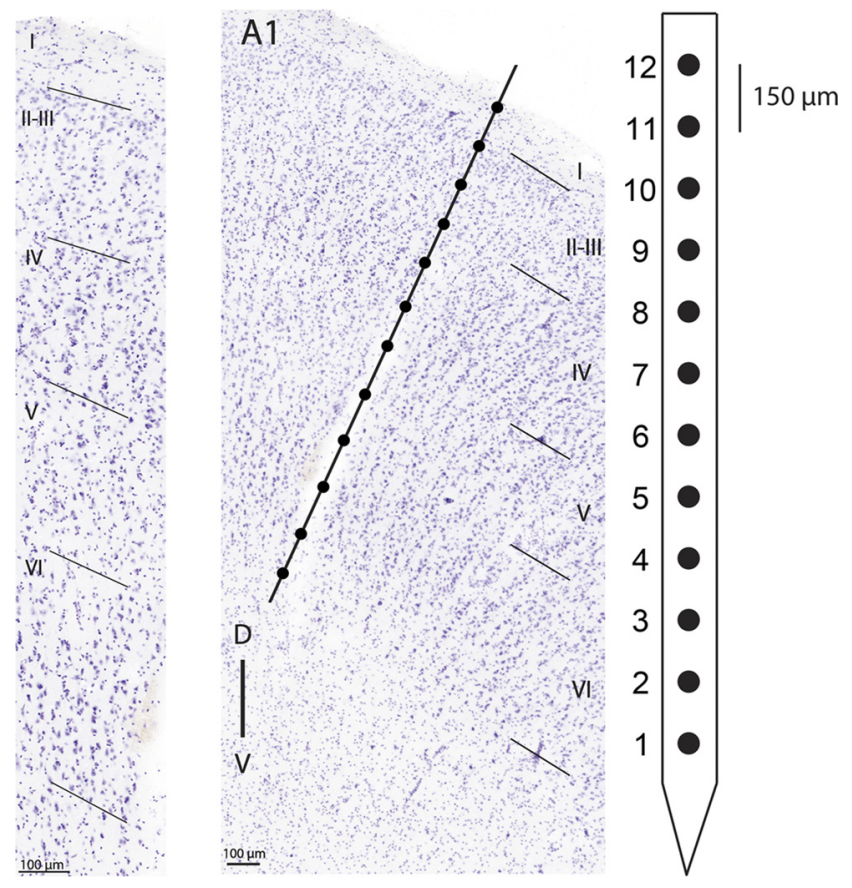

Figure 2. Left, Photomicrograph of a Nissl-stained coronal section showing A1 laminar organization. Layers are labeled with roman numerals and boundaries are marked with oblique lines. Center, Photomicrograph of a Nissl-stained coronal section highlighting a recording electrode track. Line illustrates putative location of a 12-channel recording electrode. Cortical layers are labeled with roman numerals and marked with oblique lines. Right, Schematic illustration of recording electrode channel number and spacing.

the technique induces localized hypothermia in a restricted region of the brain. The locus of the deactivation is kept small by the constant perfusion of warm blood into, and around, the cooled region. The cooling disrupts calcium channel function in the presynaptic terminal and disrupts normal neurotransmitter release (for review, see Brooks, 1983).

Deactivation of A1 and/or AAF was achieved by pumping methanol through Teflon tubing connected to the cryoloops. The tubing was immersed in a methanol dry ice bath that resulted in subzero temperatures. After passing through the cryoloop, the cooled methanol was returned to a reservoir tank (Lomber et al., 1999). Loop temperature was monitored, via a wireless thermometer (Omega, model UWTC-2), from outside the acoustic chamber and controlled within $1^{\circ} \mathrm{C}$ by altering the rate of methanol flow. The microthermocouple was located at the union of the cryoloop on the surface of the cerebrum. In the mammalian cerebrum, synaptic transmission is blocked at temperatures $<20^{\circ} \mathrm{C}$ (Bénita and Condé, 1972; Adey, 1974). Acoustically evoked activity throughout the full thickness of cortex beneath the cryoloop was eliminated by maintaining the cooling loop at $3^{\circ} \mathrm{C}$. This temperature reliably places the $20^{\circ} \mathrm{C}$ thermocline at the base of layer VI (Lomber and Payne, 2000; Lomber et al., 2007; Palmer et al., 2007; Nakamoto et al., 2008). The effective spread of cooling was restricted to $2 \mathrm{~mm}$, and thus each A1 or AAF cryoloop $(3 \times$ $6 \mathrm{~mm}$ in dimension), deactivated an estimated volume of $70-75 \mathrm{~mm}^{3}$.

Neuronal activity was recorded during nine cooling phases: (1) A1: warm, AAF: warm; (2) A1: cooling, AAF: warm; (3) A1: cool, AAF: warm; (4) A1: cool, AAF: cooling; (5) A1: cool, AAF: cool; (6) A1: rewarming, AAF: cool; (7) Al: rewarm, AAF: cool; (8) Al: rewarm, AAF: rewarming; and (9) A1: rewarm, AAF: rewarm (Fig. 1D). Each phase of a recording cycle lasted for $5 \mathrm{~min}$ (noise exposure), $30 \mathrm{~min}$ (FM Sweep), or $\sim 17 \mathrm{~min}$ (pure tones), ensuring ample time for neuronal deactivation and reactivation to occur. Recording cycles commenced with a supplemental dose of sodium pentobarbital to ensure that the highest levels of neuronal suppression produced by anesthesia were acquired during the first (A1: warm, AAF: warm) stage of each cycle, and that possible reductions in response activity induced by cooling conditions could not be attributed to anesthetic levels. 

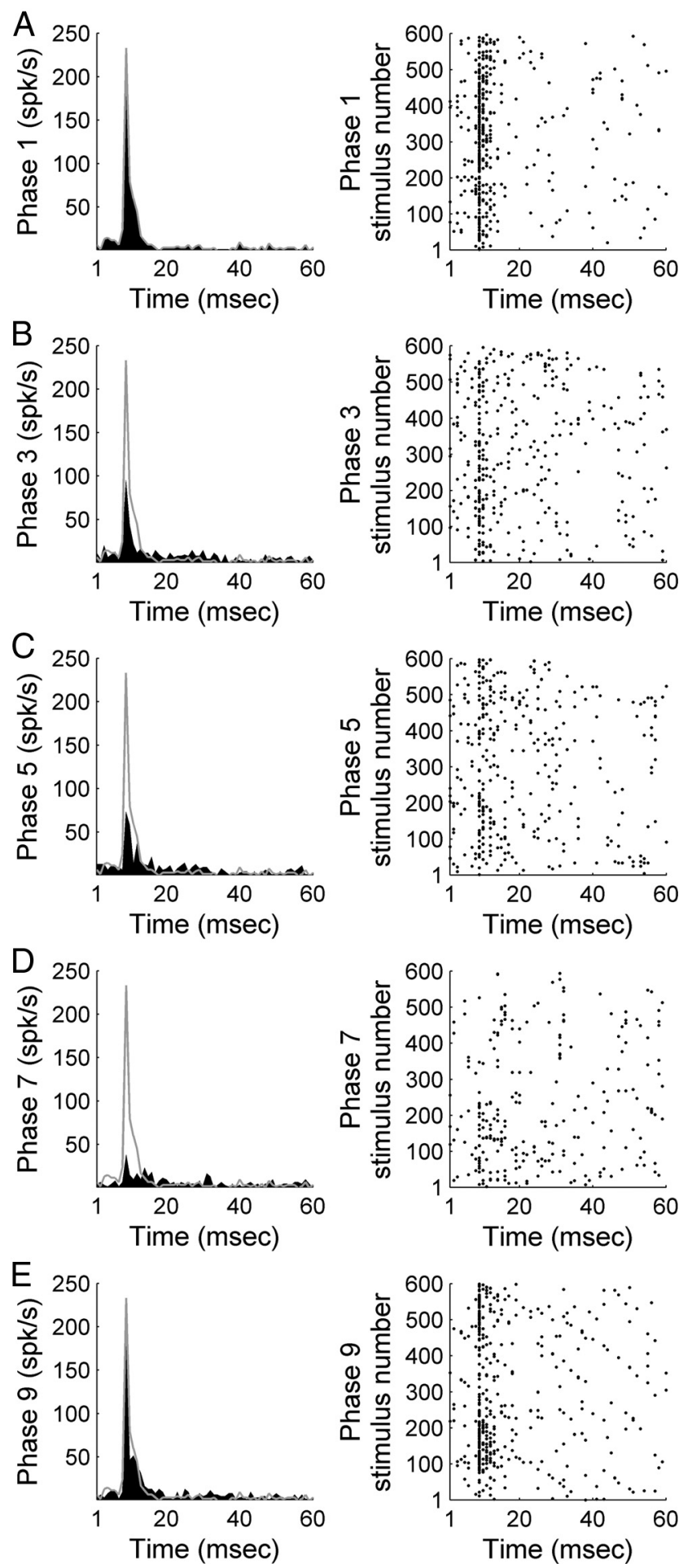

Figure 3. Representative example of A1 response strength during white noise burst exposure before, during, and after contralateral deactivation of core auditory areas. PSTH and corresponding raster example of a single-unit in A1 before contralateral cooling (phase $1, A$ ), during contralateral A1 cooling (phase $3, \boldsymbol{B}$ ), during simultaneous contralateral A1 and AAF cooling (phase 5, C), during contralateral AAF cooling (phase 7, D), and after contralateral cooling periods (phase 9, E). Gray lines across left column delineate warm (top, phase 1) response level to facilitate comparisons across cooling conditions.

Recording procedures. Iridium axial array microelectrodes (FHC; model AM-003, $200 \mu \mathrm{m}$ diameter) with impedances between 1 and 3 $\mathrm{M} \Omega$ were used to measure extracellular neuronal response activity across cortical laminae using Tucker-Davis Technologies OpenEx software.
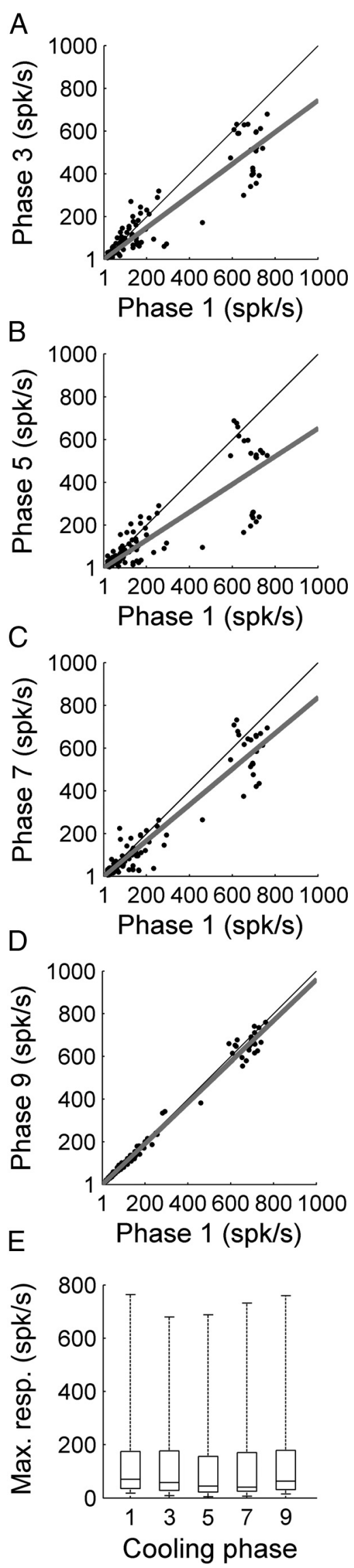

Figure 4. Comparison of A1 peak response strength during white noise burst exposure before, during, and after contralateral deactivation of core auditory areas. $A$, Peak response 
Each electrode array contained 12 recording sites linearly spaced $150 \mu \mathrm{m}$ apart (Fig. 2). The distance from the tip of the microelectrode to the first recording site was $0.5 \mathrm{~mm}$, hence, to acquire neuronal responses from all layers of auditory cortex, electrodes were lowered $\sim 2.4 \mathrm{~mm}$ from the cortical surface, or until the deepest and most superficial recording channels in the array exhibited neuronal activity. This determination is supported by histological reports identifying cat Al cortical thickness to be $\sim 1900 \mu \mathrm{m}$ (layer I, $\sim 150 \mu \mathrm{m}$ thick; layer II, $\sim 250 \mu \mathrm{m}$ thick; layer III, $\sim 500 \mu \mathrm{m}$ thick; layer IV, $\sim 250 \mu \mathrm{m}$ thick; layer V, $\sim 400 \mu \mathrm{m}$ thick; and layer VI $<400 \mu \mathrm{m}$ thick; Winer, 1992. While assessment of variations in response properties across individual cortical layers was intended, uncertainty of exact electrode depth position induced by corticovascular pulsations, dimpling of cortical tissue during electrode penetration, and swelling or depression of brain tissue throughout recording sessions, resulted in intolerable levels of recording depth ambiguity. Consequently, recording locations were classified as coming from superficial $(\sim 150-600 \mu \mathrm{m}$, electrodes $9-12)$, middle $(\sim 750-1200 \mu \mathrm{m}$, electrodes $5-8)$, or deep ( $\sim 1350-1800 \mu \mathrm{m}$, electrodes 1-4) cortical layers (Fig. 2). Cortical penetrations were limited to the middle ectosylvian gyrus, lateral to the middle suprasylvian sulcus (the dorsal zone of auditory cortex), posterior to the anterior ectosylvian sulcus, and anterior to the posterior ectosylvian sulcus. Neuronal activity was bandpass filtered $(500-5,000$ $\mathrm{Hz}$ ), amplified $(\times 10,000)$, and digitized at $25,000 \mathrm{~Hz}$ (Tucker Davis Technologies, model RZ2).

Perfusion and histological processing. At the conclusion of electrophysiological recordings, animals were deeply anesthetized with sodium pentobarbital (40 mg/kg, i.v.). Heparin (an anticoagulant) and 1\% sodium nitrite (a vasodilator) were coadministered intravenously. Each animal was perfused through the ascending aorta with saline $(1 \mathrm{~L})$, followed by $4 \%$ paraformaldehyde ( $2 \mathrm{~L}$ ), and finally $10 \%$ sucrose. All solutions were buffered at $\mathrm{pH} 7.4$ and infused at a rate of $100 \mathrm{ml} / \mathrm{min}$. The net effect of the procedure was to exsanguinate the cat, a method which complies with the recommendations of the American Veterinary Medical Association Panel on Euthanasia (Beaver et al. 2001), and to prepare scientifically useful tissue. The brain was exposed and the head was placed in a stereotaxic apparatus. To ensure correct orientation for sectioning and inclusion of the entire auditory cortex, the brain was blocked at Horsley and Clarke (1908) coronal level A23, before removal from the cranium. To cryoprotect the tissue, each brain was placed in $30 \%$ sucrose until it sunk. Frozen sections were cut $(60 \mu \mathrm{m})$ in the coronal plane and collected serially. Sections from the first of six series, at $300 \mu \mathrm{m}$ intervals, were processed for SMI-32 immunoreactivity (Sternberger Monoclonal; Mellott et al., 2010). Adjacent sections were stained for the presence of Nissl bodies (cresyl violet stain) or cytochrome oxidase (Payne and Lomber 1996). SMI-32 staining was used to confirm that electrode penetrations were made into A1. Cresyl violet staining was used to determine the laminar position of the recording sites, and cytochrome oxidase was used to confirm that the tissue beneath the cooling loops was metabolically healthy and functional. Sections were mounted on gelatinized slides, air dried, dehydrated, and coverslipped. Examination of sections for detection of electrode tracks was conducted under a Nikon E600 Eclipse microscope (Nikon Instruments; Fig. 2) equipped with a three-axis computer-controlled stepping motor system $(0.1 \mu \mathrm{m}$ resolution) coupled to a personal computer and color CCD camera (Optronix). High-$$
\leftarrow
$$

strength of A1 single units before (abscissa) and during (ordinate) contralateral A1 cooling (phase 3). $\boldsymbol{B}$, Peak response strength of A1 single units before (abscissa) and during (ordinate) simultaneous A1 and AAF contralateral deactivation (phase 5). C, Peak response strength of A1 single units before (abscissa) and during (ordinate) contralateral AAF deactivation (phase 7). $\boldsymbol{D}$, Peak response strength of A1 single units before (abscissa) and after (ordinate) contralateral deactivation (phase 9). $\boldsymbol{E}$, Group data are presented in box plots where horizontal box lines illustrate lower quartile, median, and upper quartile values and whiskers extend to most extreme data values. Statistical significance decreases from baseline (phase 1) measures ( $n=131$ single units, Kruskal-Wallis tests, $p<0.05$, followed by post hoc Tukey-Kramer corrections) were identified in phase 5 . Least-square regression lines are plotted in gray $(\boldsymbol{A}-\boldsymbol{D})$, and cooling phases are explained in Figure $1 D$.
}

resolution photomicrographs were acquired using Neurolucida software (Microbrightfield).

In each case, we verified that surgical procedures, cryoloop contact with the cerebrum, and cortical cooling operation did not disrupt the normal structural or functional integrity of cortex (Lomber et al., 1999; Yang et al., 2006). In every instance, cell and myelin stains were rich, and the cyto- and myelo-architecture of AAF or Al were characteristic of the region investigated, with no signs of pathology, as might be revealed by a marked pale staining of neurons or gliosis or light staining of cytochrome oxidase (Lomber and Payne, 1996).

Confirmation of $A 1$ and $A A F$ deactivation. Ideally, the locations of AAF and A1 would have been determined before cryoloop placement by performing detailed tonotopic mapping to ascertain the borders of the two areas. However, as this mapping would have severely compromised the integrity of cortex, precise dissociation between damage caused by recording procedures or cooling deactivation would have been unfeasible. The placement of the loops was guided by comparing the results of a number of mapping studies and determining characteristic locations for $\mathrm{AAF}$ and A1 based on gyral and sulcal patterns (Fig. 1). Therefore, as techniques to confirm the location of AAF and Al could not be used to localize the two areas before implantation, we confirmed the location of the two areas during postmortem analysis. To accomplish this, we examined SMI-32 staining patterns to determine the location of areas A1 and $\mathrm{AAF}$ and compared them with the thermal images acquired to determine the extent of cortical surface deactivation. In each case we identified that the region of deactivated corresponded quite well with the location of $\mathrm{AAF}$ or $\mathrm{A} 1$ as determined by postmortem tissue analysis.

Data analysis. Off-line single-unit sorting was completed using k-mean clustering (Tucker-Davis Technologies OpenSort) with subsequent manual inspection of unit separation. In an effort to lessen possible inaccuracies in response clustering, only one well isolated single-unit was used per recording channel (12 channels per electrode). Neuronal recordings classified as Al based on tonotopy and response latency were used in data analyses (Merzenich et al., 1973; Knight, 1977; Reale and Imig, 1980; Carrasco and Lomber, 2011). In each phase of a cooling cycle, a PSTHs expressed in spikes per second and binned with a time resolution of $1 \mathrm{~ms}$ were constructed using a custom-made program (MATLAB; MathWorks). Peak response levels, defined as the maximum number of spikes per second within a PSTH (bin with highest response level regardless of time of occurrence) were identified and compared across cooling cycle phases. An experienced observer blind to the stimulus conditions evaluated neuronal thresholds and receptive field bandwidths. Neuronal thresholds were defined as the minimum acoustic level (dB SPL) that evoked a neuronal response (i.e., lower tip of receptive field), and bandwidth measures were defined as receptive field widths (5 dB SPL increments) above neuronal threshold level. Comparisons of peak response activity were restricted to recordings where the first (A1: warm, AAF: warm) and last (A1: rewarm, AAF rewarm) phases of a cycle did not vary by more than $\pm 20 \%$. This strict criterion reduced the possibility that changes in neuronal activity across cooling conditions were elicited by neuronal death. Kolmogorov-Smirnov tests were performed to assess standard normal distributions in the dataset. Lack of normality in some conditions impelled nonparametric statistical analyses. Kruskal-Wallis tests $(p<0.05)$ followed by post hoc Tukey-Kramer corrections were used to determine significant changes across recording conditions.

\section{Results}

\section{Overview}

The present investigation examined the effects of A1 and/or AAF neuronal deactivation on contralateral A1 activity. In short, neuronal responses to simple and complex stimuli exhibited reductions in strength during cortical deactivation periods across A1 cortical laminae. The results are described in three sections. First, we present evidence of decreases in Al response activity during epochs of contralateral deactivation. Second, we discuss variations in A1 neuronal activity with respect to cortical laminae. Last, we examine associations between neuronal response modulation and hemispheric-side deactivation. 

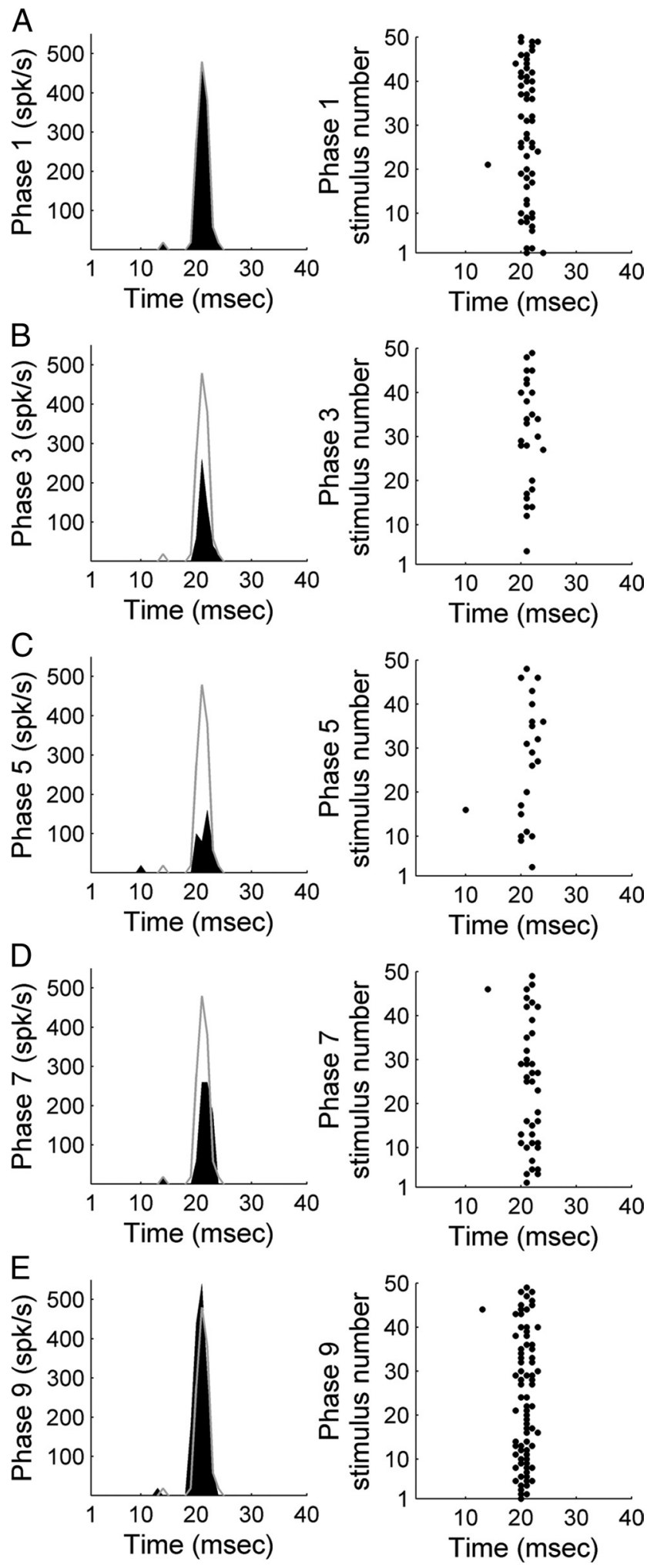

Figure 5. Representative example of A1 activity during exposure to 50 upward FM sweeps (2-16 kHz range; $\mathrm{CF} 7.34 \mathrm{kHz}$ ) before, during, and after contralateral deactivation of core auditory areas. PSTH and corresponding raster example of a single unit in A1 before contralateral cooling (phase $1, \boldsymbol{A}$ ), during contralateral A1 cooling (phase $3, \boldsymbol{B}$ ), during simultaneous contralateral A1 and AAF cooling (phase 5, C), during contralateral AAF cooling (phase 7, D), and during the contralateral rewarm stage (phase $9, \boldsymbol{E}$ ). Gray lines across left column delineate warm (top, phase 1) response level to facilitate comparisons across cooling conditions.
A Upward FM sweep
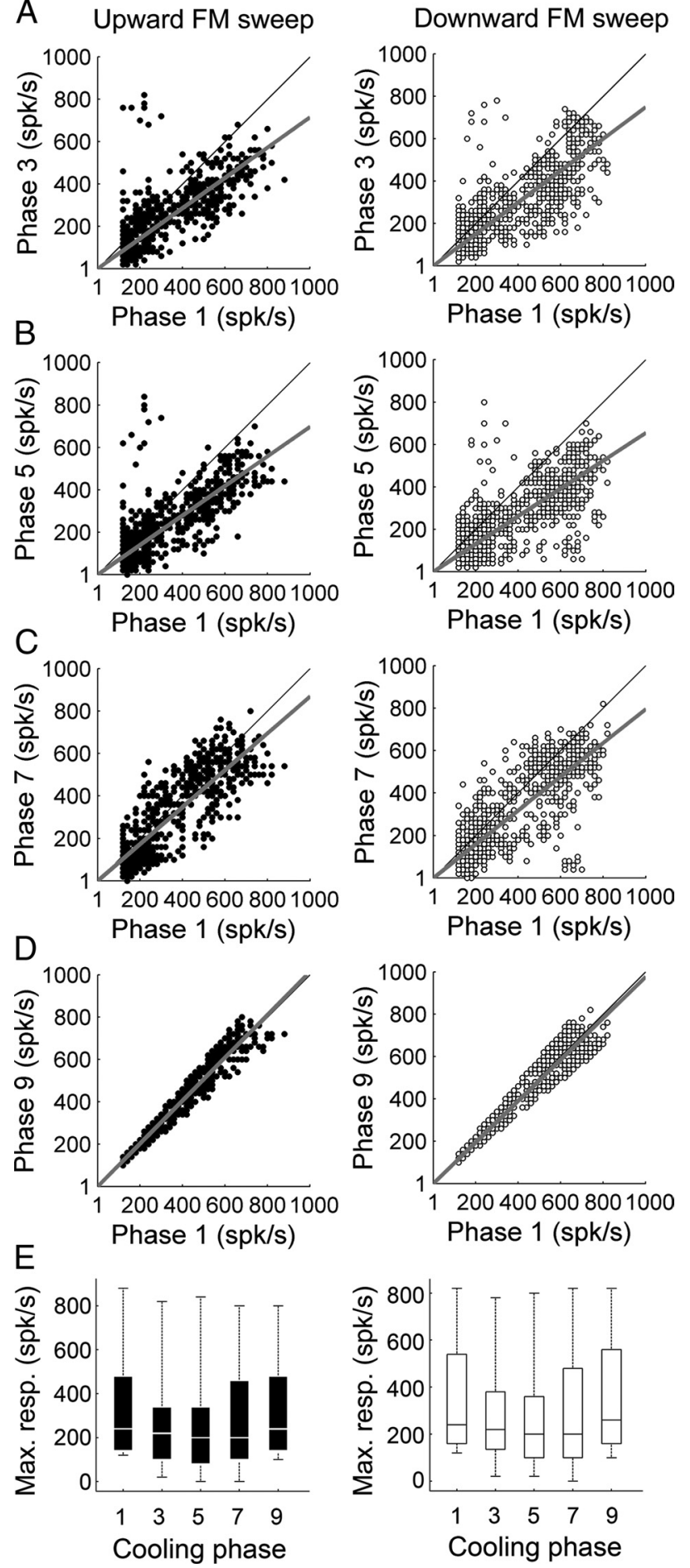

Figure 6. Comparison of $A 1$ peak response strength during upward and downward FM sweep exposure before, during, and after contralateral deactivation of core auditory areas. $\boldsymbol{A}$, Peak response strength of $A 1$ single units before (abscissa) and during (ordinate) contralateral A1 cooling (phase 3). B, Peak response strength of A1 single units before (abscissa) and during (ordinate) simultaneous A1 and AAF contralateral deactivation (phase 5). C, Peak response strength of $A 1$ single units before (abscissa) and during (ordinate) contralateral AAF deactivation (phase 7). D, Peak response strength of $A 1$ single units before (abscissa) and after (ordinate) contralateral deactivation (phase 9). $\boldsymbol{E}$, Group data are presented in box plot form in which horizontal box lines illustrate lower quartile, median, and upper quartile values and whiskers extend to most extreme data values. Statistical significance decreases from baseline (phase 1) peak activity measures (upward FM sweeps, $n$ (single units) $=223$; downward FM sweeps, $n$ 


\section{Effects of A1 and AAF deactivation on contralateral A1 response \\ Noise bursts}

A1 neuronal response activity induced by noise burst exposure was recorded before, during, and after contralateral A1 and/or AAF cooling epochs $(n$ (single units $)=131)$. A representative example of the effects of cooling deactivation demonstrates decreases in A1 response activity magnitude during individual and combined cooling epochs of contralateral A1 and AAF neurons (Fig. 3). On average, A1 peak response strength measures declined by $21.41 \%$ during contralateral A1 deactivation (Fig. $4 A$ ). The observed reductions were further extended to $31.78 \%(p<$ 0.05 ) during the simultaneous deactivation of A1 and AAF neurons (Fig. 4B), and measured 17.97\% during AAF deactivation alone (Fig. $4 C$ ). Decreases in response activity returned to baseline levels (warm phase) during rewarming epochs (Fig. 4D). Neuronal responses observed during phase 9 (rewarm period) emphasize the reversible nature of cooling deactivation. Collectively, these results provide evidence of excitatory influences of A1 and AAF neurons on contralateral A1 response activity to broadband acoustic stimulation (Fig. 4E).

\section{FM sweeps}

Response properties of A1 neurons to upward and downward FM sweeps were measured during periods of contralateral core auditory field deactivation. A representative example of modulatory influences of A1 and AAF silencing on contralateral A1 activity are presented in Figure 5. While substantial decreases in response levels were measured during deactivation epochs, FM sweep direction did not influence the type or magnitude of changes observed (upward sweep: $n$ (single units) $=223$, downward sweep: $n=230$ ). Comparable to variations measured during noise burst exposure, silencing of contralateral A1 neurons elicited on average a $22.84 \%$ (23.88\% upward sweep, $21.80 \%$ downward sweep, $p<0.05$ ) decline in A1 peak response measures (Fig. 6A), concurrent deactivation of contralateral $\mathrm{A} 1$ and AAF neurons resulted in a $32.48 \%$ (33.36\% upward sweep, 31.60\% downward sweep, $p<0.05$ ) decrease in A1 peak activity levels (Fig. 6B), and silencing of AAF neurons alone induced a 27.48\% (27.73\% upward sweep, 27.23\% downward sweep, $p<0.05$ ) decrease in A1 peak activity (Fig. 6C). Response magnitude returned to baseline (warm phase) during rewarmed epochs (Fig. 6D). Together, the observed variations in neuronal activity demonstrate that on average, contralateral deactivation of core auditory fields results in significant reductions of A1 peak activity levels during FM sweeps stimulation regardless of sweep direction (Fig. 6E).

\section{Pure tones}

Changes in A1 activity produced by contralateral A1 and/or AAF deactivation were investigated during pure tone exposure. In total, 2064 tones varying in frequency and intensity were presented at each recording location. Consistent with neuronal activity changes observed during noise burst and FM sweep exposure, presentation of tonal stimuli during contralateral cooling resulted in A1 peak activity strength reductions ( $n$ (single units) $=$ 174). Figure 7 displays a representative example of A1 response activity changes during epochs of contralateral cooling of core auditory areas. In particular, deactivation of contralateral A1

\footnotetext{
(single units) $=230$, Kruskal-Wallis tests, $p<0.05$, followed by post hoc Tukey-Kramer corrections) were identified in phases 3,5 , and 7 in both acoustic conditions. Least-square regression lines are plotted in gray $(\boldsymbol{A}-\boldsymbol{D})$, and cooling phases are explained in Figure $1 D$.
}

neurons induced on average an $8.11 \%$ decrease in A1 peak response levels (Fig. 8A). The detected decrease was further extended during the combined deactivation of A1 and AAF neurons to $20.73 \%$ ( $p<0.05$ ) (Fig. $8 B$ ), and dropped to $16.86 \%$ ( $p<$ 0.05 ) during AAF deactivation alone (Fig. $8 C$ ). A1 activity returned to baseline levels (warm phase) during the rewarm phase of the cycle (Fig. 8D). Together, these results demonstrate excitatory influences of contralateral core auditory area neurons on A1 response activity (Fig. $8 E$ ).

In addition to variations in response strength, changes in receptive field properties were examined during contralateral deactivation. Specifically, threshold levels and bandwidth measures were compared before, during, and after deactivation epochs. Despite lack of statistical significant changes in receptive field bandwidth measures during cooling periods (Figs. 9, 10) on average, neuronal thresholds increased by 2.64, $6.90(p<0.05)$, and $4.91(p<0.05) \mathrm{dB}$ SPL during cooling deactivation periods of contralateral A1, A1 and AAF, and AAF alone, respectively (Fig. 10). Collectively, these results indicate that, while response strength in A1 may be modulated by inputs from contralateral core auditory cortex, some properties of receptive fields may not be modulated by neurons in contralateral hemisphere core auditory fields.

In comparing the results from the three stimulus classes (noise burst, FM sweeps, and pure tones), two general observations can be made. First, the largest decrease in response levels in A1, regardless of stimulus class, was during the simultaneous deactivation of A1 and AAF in the contralateral hemisphere. This reduction was most profound for noise bursts and FM sweeps, where the drop was $>30 \%$. Second, for noise bursts and FM sweeps, the magnitude of the reduction in response levels during deactivation of either A1 or AAF was similar. However, this was not the case for pure tone stimuli, where the reduction in A1 response strength during contralateral AAF deactivation was twice that identified during contralateral A1 deactivation. Therefore, the deactivation of contralateral core areas has both general and specific effects on A1 neuronal responses.

\section{Laminar features}

Changes in neuronal response strength during contralateral deactivation were examined with respect to A1 laminae. Similar numbers of units were sampled across the 12 recording sites that spanned the full thickness of A1 from the deepest recording site (electrode 1) to the most superficial recording site (electrode 12; Fig. 11A). Decreases in response activity levels across acoustic signals (noise bursts, FM sweeps, and pure tones) permitted the grouping and analysis of laminar response characteristics regardless of stimulus spectral features. Recording were classified as deep (electrode 1-4), mid (electrode 5-8), or superficial (electrode 9-12) laminae. Group analyses revealed reductions in response level of $17.43 \%$ in deep, $8.46 \%$ in mid, and $11.53 \%$ across superficial layers during contralateral A1 deactivation (Fig. 11B). Concurrent A1 and AAF deactivation resulted in a decrease of $26.27 \%$ in deep, $20.89 \%$ in mid, and $24.42 \%$ in superficial layers peak response measures (Fig. $11 C$ ). AAF deactivation alone resulted in a reduction of $21.52 \%$ in deep, $17.37 \%$ in mid, and $15.64 \%$ in superficial layers peak response activity (Fig. 11D). Statistical analyses of peak response change across cortical laminae revealed significant differences between deep and mid layers during A1 deactivation (Kruskal-Wallis tests, $p<0.05$, followed by post hoc Tukey-Kramer corrections). Furthermore, examination of the relationship between field of deactivation and response change demonstrated that simultaneous deactivation of A1 and AAF neurons results in significantly larger decreases in 

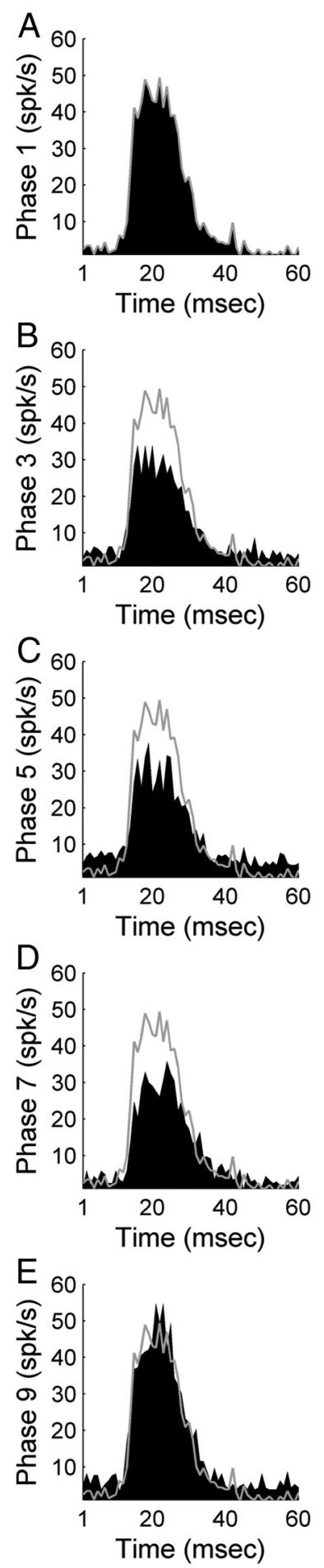
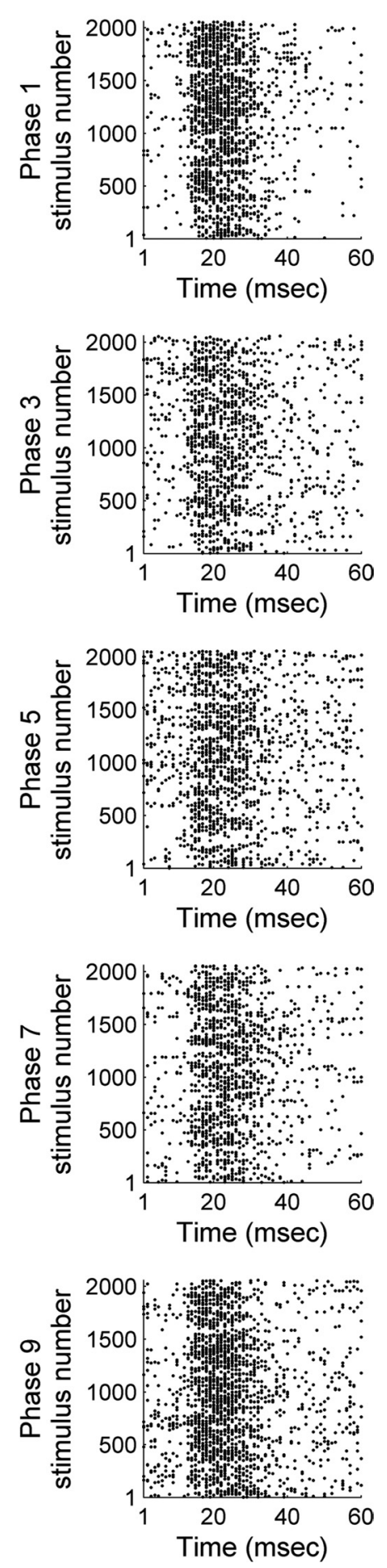

Figure 7. Representative example of A1 activity during exposure to pure tones of various frequencies and amplitudes before, during, and after contralateral deactivation of core auditory areas. PSTH and corresponding raster example of a single unit in $\mathrm{A} 1$ (CF: $4 \mathrm{kHz}$ ) before contralateral cooling (phase $1, \boldsymbol{A})$, during contralateral $A 1$ cooling (phase $3, \boldsymbol{B}$ ), during simultaneous contralateral $A 1$ and AAF cooling (phase 5, C), during contralateral AAF cooling (phase 7, D), and during contralateral rewarm periods (phase $9, \boldsymbol{E}$ ). Gray lines across left column delineate warm (top, phase 1) response level to facilitate comparisons across cooling conditions.

peak activity across deep, mid, and superficial layers than those measured during individual deactivation of A1 or AAF neurons (Kruskal-Wallis tests, $p<0.05$, followed by post hoc TukeyKramer corrections (Fig. 12). In contrast, variations between in-
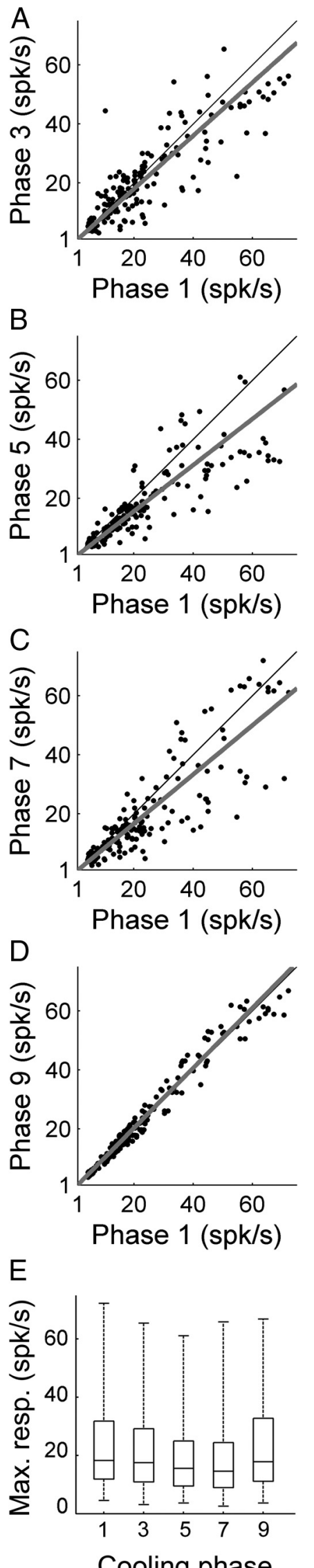

Figure 8. Comparison of $A 1$ peak response strength during pure tone exposure before, during, and after contralateral deactivation of core auditory areas. $A$, Peak response strength of $A 1$ 

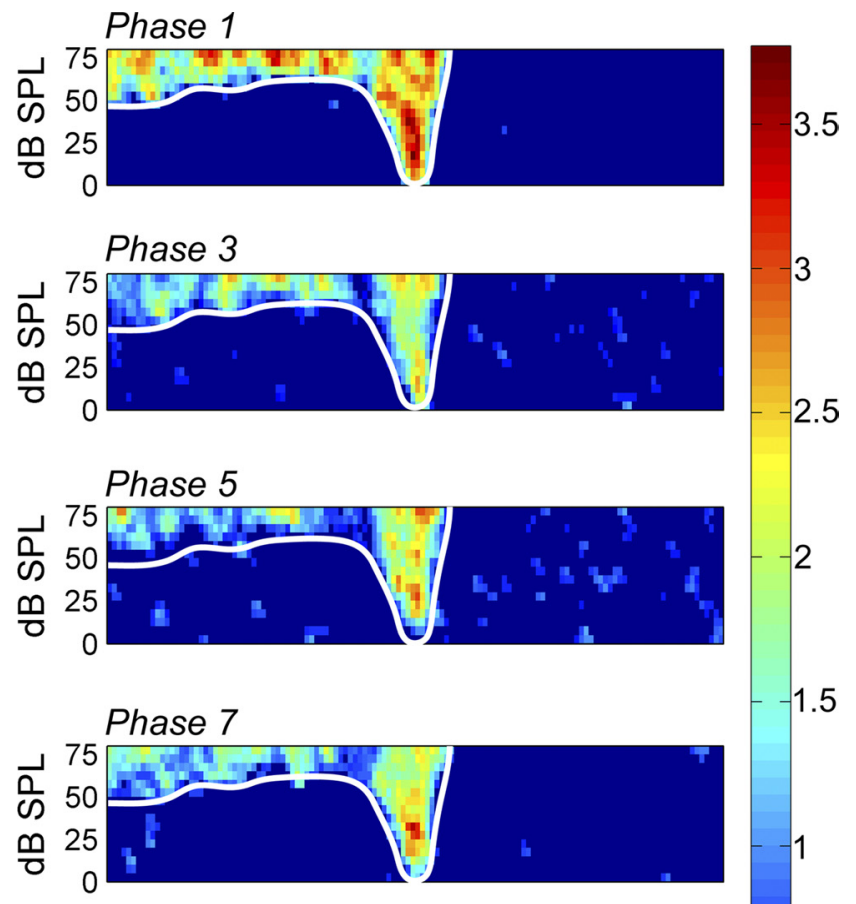

$-1.5$

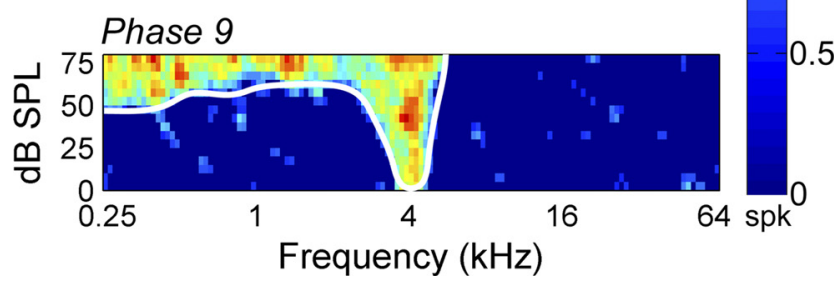

Figure 9. Representative effect of cooling deactivation on receptive field properties. Panels from top to bottom illustrate receptive field features before cooling deactivation (phase 1), during contralateral A1 deactivation (phase 3 ), during simultaneous contralateral $A 1$ and AAF deactivation (phase 5), during contralateral AAF deactivation alone (phase 7), and after cooling deactivation (phase 9, rewarm phase). Receptive field borders before cooling (white trace) are illustrated across all phases for comparative purposes. Note the lack of bandwidth variance between warm, cool, and rewarm epochs. Corresponding PSTH activity is presented in Figure $4 A$.

dividual deactivation of A1 and AAF neurons was not observed. Overall, decreases in neuronal activity across A1 laminae appear to reflect previously described interhemispheric anatomical connections, with the largest inputs targeting supragranular and infragranular layers and the weakest terminations projecting to the granular cell layer (Kelly and Wong, 1981; Code and Winer, 1986; Aitkin et al., 1988; Fig. 12).

These observations demonstrate that while the principal commissural input to auditory areas emanate from homotopic corti-

single units before (abscissa) and during (ordinate) contralateral A1 cooling (phase 3). B, Peak response strength of $A 1$ single units before (abscissa) and during (ordinate) simultaneous $A 1$ and $A A F$ contralateral deactivation (phase 5). $C$, Peak response strength of $A 1$ single units before (abscissa) and during (ordinate) contralateral AAF deactivation (phase 7). D, Peak response strength of A1 single units before (abscissa) and after (ordinate) contralateral deactivation (phase 9). $\boldsymbol{E}$, Group data are presented in box plots where horizontal box lines illustrate lower quartile, median, and upper quartile values and whiskers extend to lower and upper limits of the most extreme data values. Statistical significance decreases from baseline (phase 1) levels ( $n=174$ single units, Kruskal-Wallis tests, $p<0.05$, followed by post hoc Tukey-Kramer corrections) were identified in phases 5 and 7 . Least-square regression lines are plotted in gray $(A-D)$, and cooling phases are explained in Figure $1 D$.
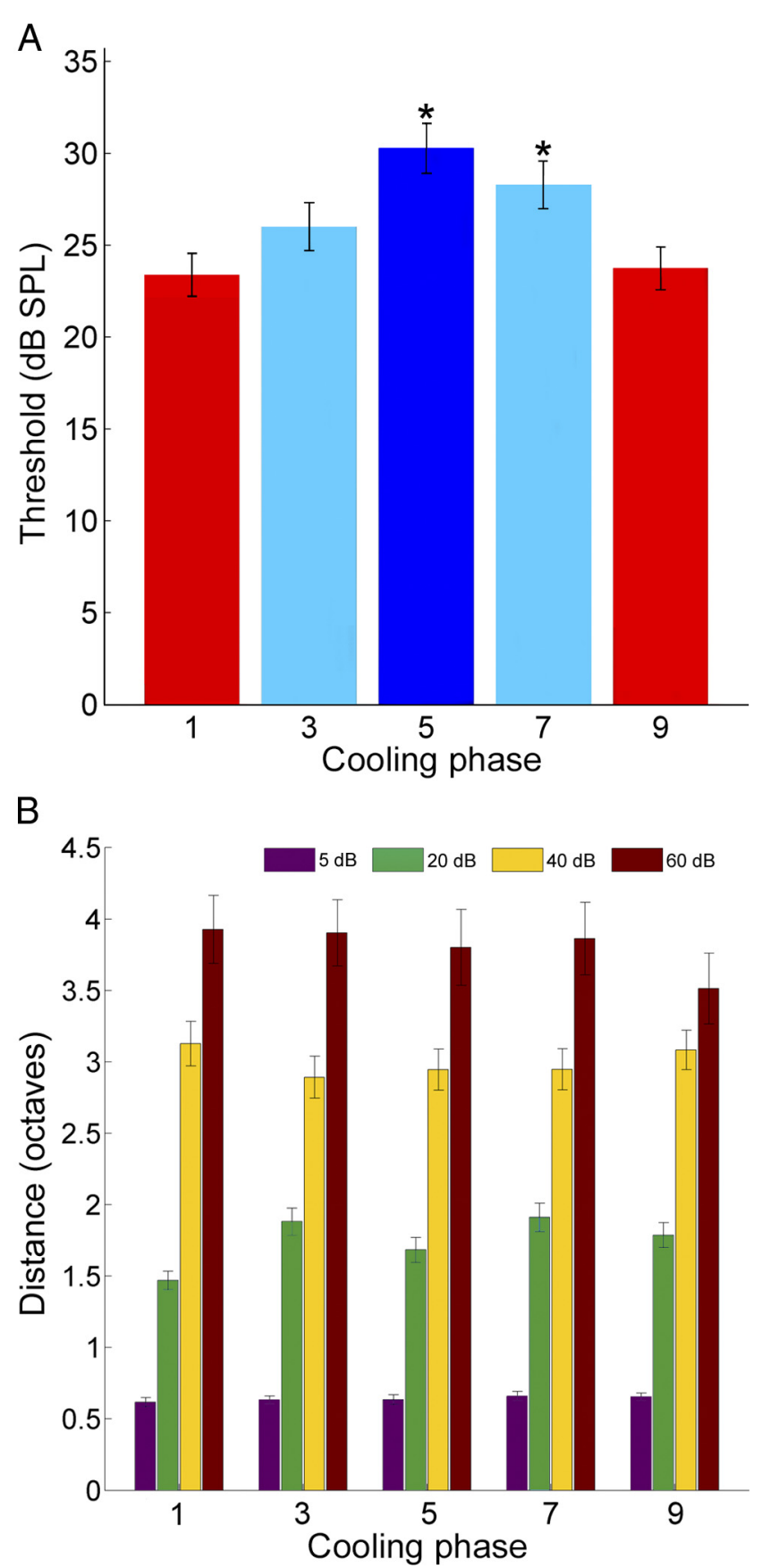

Figure 10. A, Average neuronal response threshold levels of A1 single units before cooling deactivation (phase 1), during contralateral A1 deactivation (phase 3), during simultaneous A1 and AAF deactivation (phase 5), during AAF deactivation alone (phase 7), and subsequent to cooling periods (phase 9 , rewarm phase). Statistical significance increases from baseline levels (phase 1) were identified in phases 5 and 7 ( $n=174$ single units, Kruskal-Wallis tests, ${ }^{*} p<$ 0.05 , followed by post hoc Tukey-Kramer corrections). Error bars indicate SE. Bar colors represent cooling stages: red, warm and rewarm epochs; light blue, single field cooling deactivation; dark blue, combined A1 and AAF cooling deactivation). B, Group analysis of A1 receptive field bandwidths before, during, and after contralateral cooling deactivation epochs. Bandwidth measures are illustrated at four intensities above neuronal threshold. Note the lack of variation across conditions. Error bars indicate $\mathrm{SE}, n=174$.

cal loci $(\mathrm{A} 1 \rightarrow \mathrm{A} 1)$, areas with smaller projections $(\mathrm{AAF} \rightarrow \mathrm{A} 1) \mathrm{can}$ generate comparable changes in response magnitude (Lee and Winer, 2008a). This apparent contradiction between structural and functional characteristics can be explained by known properties of corticocortical connectivity between A1 and AAF 

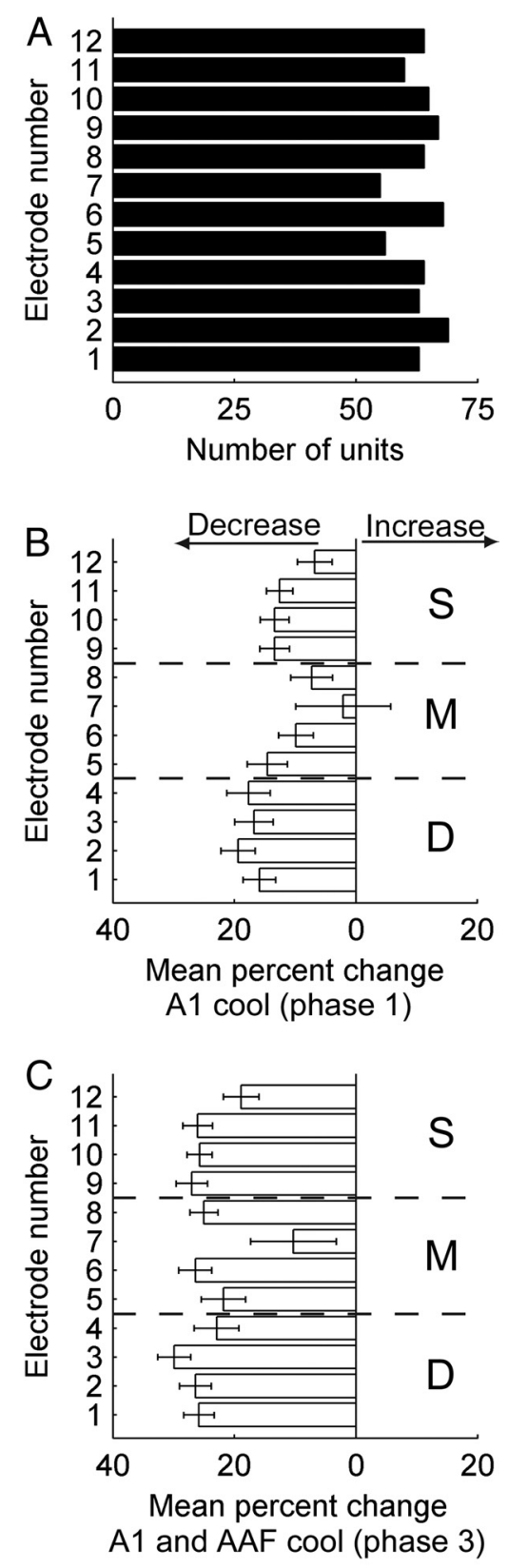

D

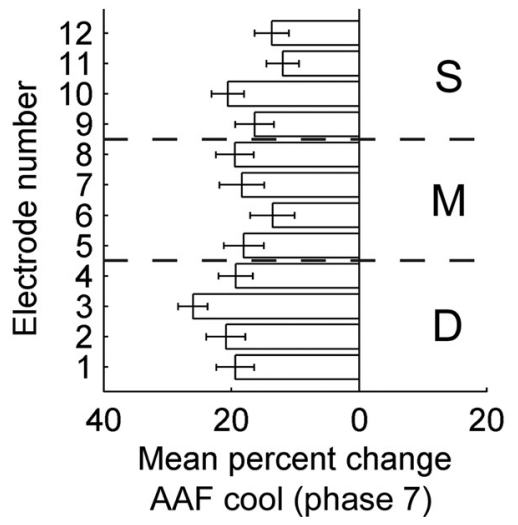

Figure 11. Mean percentage change in peak response strength across $\mathrm{A} 1$ cortical thickness before, during, and after contralateral A1 and/or AAF cooling deactivation. $A$, Number $(n=$ 758) of A1 single units measured during contralateral deactivation with respect to cortical depth. $\boldsymbol{B}$, Mean percentage change in peak response strength of $A 1$ neurons across laminae

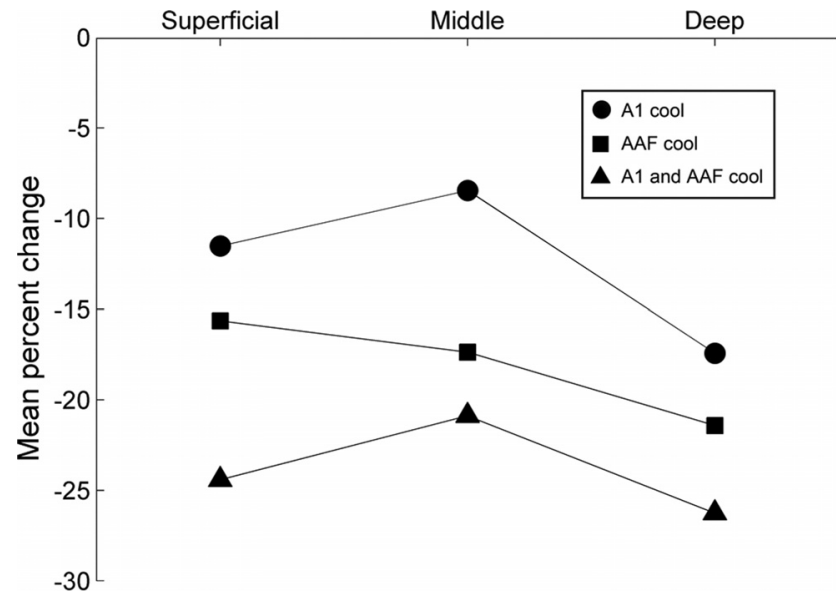

Figure 12. Trends in peak response change across $A 1$ laminae during contralateral $A 1$ and/or AAF cooling deactivation. Note that the simultaneous deactivation of A1 and AAF resulted in higher levels of response change than during periods of $A 1$ or AAF cooling deactivation alone. Also, notice that in two of the three conditions investigated middle layers revealed a smaller degree of response change than those observed in deep and superficial laminae.

neurons. Specifically, it has been demonstrated that AAF deactivation results in significant decreases in response activity across ipsilateral A1 neurons (Carrasco and Lomber, 2009b). Therefore, AAF deactivation can influence response properties of contralateral A1 neurons through direct commissural connections as well as indirect projections via ipsilateral A1. Based on this model, the results of the present investigation are not surprising and corroborate known structural and functional properties of auditory cortex connectivity. In particular, as predicted from connectional reports (Lee and Winer, 2008a, b), the highest influence in A1 neuronal response activity was observed during the combined deactivation of A1 and AAF neurons. The magnitude of these changes was followed by AAF deactivation via direct and indirect connections to A1. Last, deactivation of A1 resulted in the lowest levels of response reduction in contralateral A1 neuronal activity.

\section{Hemispheric lateralization}

So far, neuronal recording from both hemispheres have been grouped and analyzed together making the examination of hemispheric dominance unfeasible. Thus, in an effort to measure differences in hemispheric lateralization, recordings were classified as left or right hemisphere, and variances in Al peak response levels induced by contralateral deactivation were measured. Statistical analyses (Kruskal-Wallis tests, $p<0.05$ followed by post hoc Tukey-Kramer corrections) did not reveal significant hemispheric variations during deactivation periods (Fig. 13; left: $n=$ 324, right: $n=434$ ). In particular, deactivation of A1 in the left

$\leftarrow$

during contralateral A1 deactivation. C, Mean percentage change in peak response strength of A1 neurons across laminae during the simultaneous cooling deactivation of contralateral $A 1$ and AAF. D, Mean percentage change in peak response strength of $A 1$ neurons across laminae during contralateral AAF cooling deactivation. Numbers on the ordinate represent electrode number (150 $\mu \mathrm{m}$ apart) with 1 representing the deepest cortical electrode position (approximately layers $\mathrm{V}-\mathrm{VI}$ ) and 12 signifying the most superficial location (approximately layers I-II). Histograms $(\boldsymbol{B}-\boldsymbol{D})$ show mean \pm SEM. The only comparison across laminar groups that revealed statistical significant levels (Kruskal-Wallis tests, $p<0.05$, followed by post hoc TukeyKramer corrections) occurred between $D$ and $M$ groups during $A 1$ deactivation (B). S, superficial layers; $M$, mid layers; $D$, deep layers. Note that the number of single units totals the sum of 131 (noise), 174 (pure tones), and 453 (up and down FM sweeps) A1 single-unit recordings. Error bars indicate $S E$. 
hemisphere produced average reductions in contralateral A1 activity of $20.92 \%$ that were not significantly larger than decreases observed during right hemisphere A1 deactivation on left hemisphere A1 cells (16.81\%; Fig. 13). Similarly, concurrent deactivation of left or right hemisphere A1 and AAF elicited comparable reductions in contralateral A1 peak activity (28.29 and $22.93 \%$, respectively; Fig. 13). Last, decreases in peak response activity of right hemisphere Al neurons (16.52\%) during left hemisphere AAF deactivation were not statistically different to left hemisphere A1 response changes (14.59\%) during right hemisphere deactivation (Fig. 13). Therefore, core areas of auditory cortex in the left and right hemispheres exert comparable influences on contralateral A1 neurons. These results suggest a symmetrical relationship between auditory areas of the two cerebral hemispheres.

\section{Discussion}

Although numerous studies have examined transcallosal communication properties [visual cortex: (Glickstein and Berlucchi, 2008; Innocenti, 1980); somatosensory cortex: (Clarey et al., 1996; Rema and Ebner, 2003; Pluto et al., 2005)], to date, the effects of auditory cortex deactivation on acoustically evoked responses of contralateral cortical regions has not been reported. The present study is the first investigation to demonstrate changes in A1 response characteristics induced by reversible cooling deactivation on contralateral auditory fields. Specifically, we demonstrate that deactivation of core auditory areas (A1 and AAF) reduce acoustically evoked neuronal activity in contralateral A1 neurons.

\section{Comparison across sensory systems \\ Auditory system}

Structural studies of interhemispheric connections in cat auditory cortex have demonstrated that a large number of transcallosal projections emanating from core auditory areas A1 and AAF terminate in contralateral core auditory fields (Lee and Winer, 2008a). Nearly $90 \%$ of these projections arise from layers III and V (Ravizza et al., 1976; Kelly and Wong, 1981; Code and Winer, 1985; Games and Winer, 1988; Lee and Winer, 2008a). Auditory transcallosal projections pass through the central body, posterior body, and dorsal splenium of the corpus callosum (Lomber et al., 1994; Clarke et al., 1995) and terminate throughout layers II-VI in the homotopic cortical locus, with the greatest density of terminals found in layers II and III and with the lowest density of terminals in layer IV (Kelly and Wong, 1981; Code and Winer, 1986; Aitkin et al., 1988). In the cat, the sources and terminations of callosally projecting neurons have been related to binaural and frequency maps (Imig and Brugge, 1978; Imig et al., 1986). Similarities of origins and terminations of auditory callosal projections in other species, including rat (Cipolloni and Peters, 1983;
Games and Winer, 1988; Rüttgers et al., 1990), hamster (Ravizza et al., 1976), and marmoset (Aitkin et al., 1988) demonstrate consistency in connectivity profiles across animal models.

In contrast to the noticeable abundance of structural information available, few investigations have examined functional features of transcallosal connectivity (Mitani and Shimokouchi, 1985; Kitzes and Doherty, 1994; Bamiou et al., 2007). In a neuroanatomical report by Cipolloni and Peters (1983), it was demonstrated that interhemispheric connections form asymmetric synapses with dendritic spines of pyramidal neurons, suggesting the presence of excitatory projections across hemispheres. The results of Cipolloni and Peters (1983) were validated by an investigation of intracellular activity by Mitani and Shimokouchi (1985), which revealed that stimulation of transcallosal projecting neurons in auditory cortex commonly elicit EPSPs in contralateral auditory cortex. These investigations suggest that deactivation of auditory neurons should result in a reduction of response activity in contralateral auditory neurons as demonstrated in the present investigation. Puzzling, however, are the results of Kitzes and Doherty (1994), in which suppression of neuronal activity was achieved during contralateral electrical stimulation paired with acoustic exposure. The authors of the study proposed that stimulus pulse amplitude parameters could 
have caused the observed inhibitory effects in the experiment. Thus far, activation (Mitani and Shimokouchi, 1985), deactivation (present study), and neuroanatomical (Cipolloni and Peters, 1983) studies suggest a preponderance of interhemispheric excitatory projections in the auditory system.

\section{Visual system}

Considerable work has been conducted to identify anatomical and functional properties of interhemispheric connections in the visual system (Choudhury et al., 1965; Hubel and Wiesel, 1967; Silveira et al., 1989; Yinon, 1994; Abel et al., 2000; Schmidt et al., 2010; Genç et al., 2011; for review, see Glickstein and Berlucchi, 2008). Visual cortex investigations have implicated transcallosal projections in midline fusion (Choudhury et al., 1965; Hubel and Wiesel, 1967; Payne, 1990), midline receptive field extension (Antonini et al., 1979, 1983, 1985; Marzi et al., 1982), binocular activation (Lepore and Guillemot, 1982; Blakemore et al., 1983; Payne et al., 1984), and depth perception (Gardner and Cynader, 1987). While a conspicuous lack of comparable investigations in the auditory system impedes ample scrutiny of functional differences between these two modalities, a study conducted by Payne et al. 1991 is distinctly germane to the discussion of the present results. In the study by Payne et al. 1991 reversibly deactivation of transcallosally projecting neurons from areas 17 and 18 altered response properties of receiving neurons in the opposite hemisphere. Similar to the present investigation decreases in evoked activity during contralateral deactivation epochs were reported. Specifically, $41 \%$ of layer II/III, $40 \%$ of layer IV, and $95 \%$ of layer V/VI neurons investigated showed a decrease of at least $25 \%$ in evoked response. While much work in the auditory system is still needed to form models of transcallosal functional properties, similarities in neuronal response variation between visual and auditory systems imply commonalities of interhemispheric functional properties across modalities.

\section{Somatosensory system}

Neuroanatomical investigations in somatosensory cortex have reported transcallosal connections between homotopic regions of primary somatosensory area (S1) (Koralek and Killackey, 1990; Carr and Sesack, 1998). These anatomical observations have been functionally examined by measuring changes in S1 response activity during contralateral S1 deactivation (Clarey et al., 1996; Rema and Ebner, 2003; Pluto et al., 2005). In particular, cooling deactivation (Clarey et al., 1996), pharmacological silencing (Rema and Ebner, 2003), and surgical removal (Rema and Ebner, 2003) of S1 has been used to assess functional features of transcallosal projections. Rema and Ebner (2003) demonstrated that pharmacological deactivation or surgical removal of the vibrissa representation of SI barrel field cortex in adult rats can induce reductions in response levels of contralateral SI activity to somatic stimulation (layers II/III, 50\%; IV, 56\%; V, 66\% reduction). Similarly, cooling deactivation of primary somatosensory area (3b) in adult macaque monkeys (Macaca fascicularis) and little red flying foxes (Pteropus scapulatus) resulted in neuronal response activity suppression in the contralateral hemisphere (Clarey et al., 1996). Collectively, the findings of Clarey et al. (1996) and Rema and Ebner (2003) substantiate the results of the present investigation in the somatosensory system.

\section{Laminar and hemispheric specificity}

Laminar

In the present investigation, decreases in peak response strength were revealed across all cortical laminae. Despite this homogeneous effect, differences in response change levels were observed between laminar groups. Specifically, in all conditions investigated a trend of magnitude changes was observed to be lower in middle layers than deep layers. Similar differences were found between middle and superficial laminae during A1 and simultaneous A1 and AAF deactivation (Fig. 12). This trend in response change demonstrates that while contralateral deactivation can decrease response levels of A1 neurons across all laminae, neurons in deep and superficial laminae are more receptive to contralateral deactivation than neurons in middle layers. This result corroborates previously described anatomical connections where the largest contralateral input terminates in supragranular and infragranular layers and the weakest terminations project to the granular cells (Kelly and Wong, 1981; Code and Winer, 1986; Aitkin et al., 1988).

\section{Hemispheric}

In contrast to known origins and terminations of transcallosal pathways, little is known about how these profiles vary between hemispheres. Nonetheless, numerous studies have demonstrated differences in activation levels across hemispheres during various cognitive tasks (for review, see Samara and Tsangaris, 2011). Based on these reports, the present study was designed to investigate the possibility of asymmetries in neuronal response modulation between A1 fields across hemispheres. Our statistical analyses did not reveal significant differences between left and right hemisphere modulatory properties. Presently, the lack of anatomical information about differences in transcallosal connections between auditory cortical fields impedes comparisons of the present results with structural characteristics. Future experiments will be required to describe the putative anatomical basis of hemispheric asymmetries/symmetries in cat auditory cortex.

\section{Other considerations}

\section{Converging inputs}

Throughout the manuscript, reductions in neuronal response strength have been imputed to transcallosal projections; however, a less parsimonious explanation might attribute variations in contralateral neuronal response to an alternate pathway of auditory converging inputs. In particular, A1 efferent projections to cochlear nucleus (CN) neurons (Weedman and Ryugo, 1996) and projections from $\mathrm{CN}$ neurons to the contralateral superior olivary complex (SOC) could account for the observed phenomena (Adams and Warr, 1976; Hackney, 1987; Thompson and Thompson, 1991; Schofield and Cant, 1996; Alibardi, 2000; Arnott et al., 2004). In this alternative model, deactivation of A1 neurons elicits variations in ipsilateral $\mathrm{CN}$ activity that subsequently alters response characteristics of contralateral SOC neurons, consequently inducing neuronal response vicissitudes in (contralateral) A1 via feedforward connections. This alternative model, while still interhemispheric, does not rely on the corpus callosum, and is supported by reports of changes in midbrain neuronal activity during cortical deactivation (Nakamoto et al., 2008). Future experiments should aim at exploring the participation, or lack thereof, of alternative communicative pathways between auditory cortical fields.

\section{Anesthesia}

It is crucial to acknowledge the inability to extend the present results to awake-behaving states; however, comparisons across studies suggest plausible consistencies between awake and anesthetized states. In particular, similarities in neuronal response inhibition during contralateral deactivation has been reported in awake (Rema and Ebner, 2003), as well as anesthetized states induced by halothane (Payne et al., 1991), ketamine (Clarey et al., 
1996), and pentobarbital (present results). Furthermore, neuroanatomical and intracellular recordings support a model of response suppression during contralateral deactivation (Cipolloni and Peters, 1983; Mitani and Shimokouchi, 1985).

\section{References}

Abel PL, O'Brien BJ, Olavarria JF (2000) Organization of callosal linkages in visual area V2 of macaque monkey. J Comp Neurol 428:278-293. CrossRef Medline

Adams JC, Warr WB (1976) Origins of axons in the cat's acoustic striae determined by injection of horseradish peroxidase into severed tracts. J Comp Neurol 170:107-121. CrossRef Medline

Adey WR (1974) Biophysical and metabolic bases of cooling effects on cortical membrane potentials in the cat. Exp Neurol 42:113-140. CrossRef Medline

Aitkin LM, Kudo M, Irvine DR (1988) Connections of the primary auditory cortex in the common marmoset, Callithrix jacchus jacchus. J Comp Neurol 269:235-248. CrossRef Medline

Alibardi L (2000) Cytology, synaptology and immunocytochemistry of commissural neurons and their putative axonal terminals in the dorsal cochlear nucleus of the rat. Ann Anat 182:207-220. CrossRef Medline

Antonini A, Berlucchi G, Marzi CA, Sprague JM (1979) Importance of corpus callosum for visual receptive fields of single neurons in cat superior colliculus. J Neurophysiol 42:137-152. Medline

Antonini A, Berlucchi G, Lepore F (1983) Physiological organization of callosal connections of a visual lateral suprasylvian cortical area in the cat. J Neurophysiol 49:902-921. Medline

Antonini A, Di Stefano M, Minciacchi D, Tassinari G (1985) Interhemispheric influences on area 19 of the cat. Exp Brain Res 59:171-184. Medline

Arnott RH, Wallace MN, Shackleton TM, Palmer AR (2004) Onset neurones in the anteroventral cochlear nucleus project to the dorsal cochlear nucleus. J Assoc Res Otolaryngol 5:153-170. Medline

Bamiou DE, Sisodiya S, Musiek FE, Luxon LM (2007) The role of the interhemispheric pathway in hearing. Brain Res Rev 56:170-182. CrossRef Medline

Beaver BV, Reed W, Leary S, McKiernan B, Bain F, Schultz R, Bennett BT, Pascoe P, Schull E, Cork LC, Francis-Floyd R, Amass KD, Johnson RJ, Schmidt RH, Underwood W, Thorton GW, Kohn B (2001) 2000 Report of the American Veterinary Medical Association Panel of Euthanasia. J Am. Vet. Med. Assoc 218:669-696.

Bénita M, Condé H (1972) Effects of local cooling upon conduction and synaptic transmission. Brain Res 36:133-151. CrossRef Medline

Berlucchi G, Rizzolatti G (1968) Binocularly driven neurons in visual cortex of split-chiasm cats. Science 159:308-310. CrossRef Medline

Blakemore C, Diao YC, Pu ML, Wang YK, Xiao YM (1983) Possible functions of the interhemispheric connexions between visual cortical areas in the cat. J Physiol 337:331-349. Medline

Brooks VB (1983) Study of brain function by local, reversible cooling. Rev Physiol Biochem Pharmacol 95:1-109. CrossRef

Carr DB, Sesack SR (1998) Callosal terminals in the rat prefrontal cortex: synaptic targets and association with GABA-immunoreactive structures. Synapse 29:193-205. CrossRef Medline

Carrasco A, Lomber SG (2009a) Evidence for hierarchical processing in cat auditory cortex: nonreciprocal influence of primary auditory cortex on the posterior auditory field. J Neurosci 29:14323-14333. CrossRef Medline

Carrasco A, Lomber SG (2009b) Differential modulatory influences between primary auditory cortex and the anterior auditory field. J Neurosci 29:8350-8362. CrossRef Medline

Carrasco A, Lomber SG (2010) Reciprocal modulatory influences between tonotopic and nontonotopic cortical fields in the cat. J Neurosci 30:14761487. CrossRef Medline

Carrasco A, Lomber SG (2011) Neuronal activation times to simple, complex, and natural sounds in cat primary and nonprimary auditory cortex. J Neurophysiol 106:1166-1178. CrossRef Medline

Chafee MV, Goldman-Rakic PS (2000) Inactivation of parietal and prefrontal cortex reveals interdependence of neural activity during memoryguided saccades. J Neurophysiol 83:1550-1566. Medline

Cheung SW, Nagarajan SS, Bedenbaugh PH, Schreiner CE, Wang X, Wong A (2001) Auditory cortical neuron response differences under isoflurane versus pentobarbital anesthesia. Hear Res 156:115-127. CrossRef Medline

Choudhury BP, Whitteridge D, Wilson ME (1965) The function of the callosal connections of the visual cortex. Q J Exp Physiol Cogn Med Sci 50:214-219. Medline

Cipolloni PB, Peters A (1983) The termination of callosal fibres in the auditory cortex of the rat. A combined Golgi-electron microscope and degeneration study. J Neurocytol 12:713-726. CrossRef Medline

Clarey JC, Tweedale R, Calford MB (1996) Interhemispheric modulation of somatosensory receptive fields: evidence for plasticity in primary somatosensory cortex. Cereb Cortex 6:196-206. CrossRef Medline

Clarke S, de Ribaupierre F, Bajo VM, Rouiller EM, Kraftsik R (1995) The auditory pathway in cat corpus callosum. Exp Brain Res 104:534-540.

Code RA, Winer JA (1985) Commissural neurons in layer III of cat primary auditory cortex (AI): pyramidal and non-pyramidal cell input. J Comp Neurol 242:485-510. CrossRef Medline

Code RA, Winer JA (1986) Columnar organization and reciprocity of commissural connections in cat primary auditory cortex (AI). Hear Res 23: 205-222. CrossRef Medline

Diamond IT, Jones EG, Powell TP (1968) Interhemispheric fiber connections of the auditory cortex of the cat. Brain Res 11:177-193. CrossRef Medline

Games KD, Winer JA (1988) Layer V in rat auditory cortex: projections to the inferior colliculus and contralateral cortex. Hear Res 34:1-25. CrossRef Medline

Gardner JC, Cynader MS (1987) Mechanisms for binocular depth sensitivity along the vertical meridian of the visual field. Brain Res 413:60-74. CrossRef Medline

Genç E, Bergmann J, Tong F, Blake R, Singer W, Kohler A (2011) Callosal connections of primary visual cortex predict the spatial spreading of binocular rivalry across the visual hemifields. Front Hum Neurosci 5:161. Medline

Glickstein M, Berlucchi G (2008) Classical disconnection studies of the corpus callosum. Cortex 44:914-927. CrossRef Medline

Hackney CM (1987) Anatomical features of the auditory pathway from cochlea to cortex. Br Med Bull 43:780-801. Medline

Horsley V, Clarke RH (1908) The structure and functions of the cerebellum examined by a new method. Brain 31:45-124. CrossRef

Hubel DH, Wiesel TN (1967) Cortical and callosal connections concerned with the vertical meridian of visual fields in the cat. J Neurophysiol 30: 1561-1573. Medline

Imaizumi K, Priebe NJ, Crum PA, Bedenbaugh PH, Cheung SW, Schreiner CE (2004) Modular functional organization of cat anterior auditory field. J Neurophysiol 92:444-457. CrossRef Medline

Imig TJ, Brugge JF (1978) Sources and terminations of callosal axons related to binaural and frequency maps in primary auditory cortex of the cat. J Comp Neurol 182:637-660. CrossRef Medline

Imig TJ, Reale RA, Brugge JF, Morel A, Adrian H (1986) Topography of cortico-cortical connections related to tonotopic and binaural maps of cat auditory cortex. In: Two hemispheres-one brain: functions of the corpus callosum (Leporé F, Ptito M, Jasper HH, eds), pp 103-115. New York: Liss.

Innocenti GM (1980) The primary visual pathway through the corpus callosum: morphological and functional aspects in the cat. Arch Ital Biol 118:124-188. Medline

Jasper HH, Shacter DG, Montplaisir J (1970) The effect of local cooling upon spontaneous and evoked electrical activity of cerebral cortex. Can J Physiol Pharmacol 48:640-652. CrossRef Medline

Kelly JP, Wong D (1981) Laminar connections of the cat's auditory cortex. Brain Res 212:1-15. CrossRef Medline

Kitzes LM, Doherty D (1994) Influence of callosal activity on units in the auditory cortex of ferret (Mustela putorius). J Neurophysiol 71:1740 1751. Medline

Knight PL (1977) Representation of the cochlea within the anterior auditory field (AAF) of the cat. Brain Res 130:447-467. CrossRef Medline

Koralek KA, Killackey HP (1990) Callosal projections in rat somatosensory cortex are altered by early removal of afferent input. Proc Natl Acad Sci U S A 87:1396-1400. CrossRef Medline

Lee CC, Winer JA (2008a) Connections of cat auditory cortex: III. Corticocortical system. J Comp Neurol 507:1920-1943. CrossRef Medline

Lee CC, Winer JA (2008b) Connections of cat auditory cortex: II. Commissural system. J Comp Neurol 507:1901-1919. CrossRef Medline 
Lepore F, Guillemot JP (1982) Visual receptive field properties of cells innervated through the corpus callosum in the cat. Exp Brain Res 46:413424. Medline

Lomber SG (1999) The advantages and limitations of permanent or reversible deactivation techniques in the assessment of neural function. J Neurosci Methods 86:109-117. CrossRef Medline

Lomber SG, Payne BR (1996) Removal of two halves restores the whole: reversal of visual hemineglect during bilateral cortical or collicular inactivation in the cat. Vis Neurosci 13:1143-1156. CrossRef Medline

Lomber SG, Payne BR (2000) Translaminar differentiation of visually guided behaviors revealed by restricted cerebral cooling deactivation. Cereb Cortex 10:1066-1077. CrossRef Medline

Lomber SG, Cornwell P, Sun JS, MacNeil MA, Payne BR (1994) Reversible inactivation of visual processing operations in middle suprasylvian cortex of the behaving cat. Proc Natl Acad Sci U S A 91:2999-3003. CrossRef Medline

Lomber SG, Payne BR, Horel JA (1999) The cryoloop: an adaptable reversible cooling deactivation method for behavioral or electrophysiological assessment of neural function. J Neurosci Methods 86:179-194. CrossRef Medline

Lomber SG, Malhotra S, Hall AJ (2007) Functional specialization in nonprimary auditory cortex of the cat: areal and laminar contributions to sound localization. Hear Res 229:31-45. CrossRef Medline

Marzi CA, Antonini A, Di Stefano M, Legg CR (1982) The contribution of the corpus callosum to receptive fields in the lateral suprasylvian visual areas of the cat. Behav Brain Res 4:155-176. CrossRef Medline

Mellott JG, Van der Gucht E, Lee CC, Carrasco A, Winer JA, Lomber SG (2010) Areas of the cat auditory cortex as defined by neurofilament proteins expressing SMI-32. Hear Res 267:119-136. CrossRef Medline

Merzenich MM, Knight PL, Roth GL (1973) Cochleotopic organization of primary auditory cortex in the cat. Brain Res 63:343-346. CrossRef Medline

Mitani A, Shimokouchi M (1985) Neuronal connections in the primary auditory cortex: an electrophysiological study in the cat. J Comp Neurol 235:417-429. CrossRef Medline

Morel A, Garraghty PE, Kaas JH (1993) Tonotopic organization, architectonic fields, and connections of auditory cortex in macaque monkeys. J Comp Neurol 335:437-459. CrossRef Medline

Nakamoto KT, Jones SJ, Palmer AR (2008) Descending projections from auditory cortex modulate sensitivity in the midbrain to cues for spatial position. J Neurophysiol 99:2347-2356. CrossRef Medline

Olfert ED, Cross BM, McWilliam AA (1993) Guide to the care and use of experimental animals. Canadian Council on Animal Care, Ottawa, Ontario.

Olshausen BA, Field DJ (2004) Sparse coding of sensory inputs. Curr Opin Neurobiol 14:481-487. CrossRef Medline

Palmer AR, Hall DA, Sumner C, Barrett DJ, Jones S, Nakamoto K, Moore DR (2007) Some investigations into non-passive listening. Hear Res 229: 148-157. CrossRef Medline

Payne BR (1990) Function of the corpus callosum in the representation of the visual field in cat visual cortex. Vis Neurosci 5:205-211. CrossRef Medline

Payne BR, Lomber SG (1996) Age dependent modification of cytochrome oxidase activity in the cat dorsal lateral geniculate nucleus following removal of primary visual cortex. Vis Neurosci 13:805-816. CrossRef Medline

Payne BR, Pearson HE, Berman N (1984) Role of corpus callosum in functional organization of cat striate cortex. J Neurophysiol 52:570-594. Medline
Payne BR, Siwek DF, Lomber SG (1991) Complex transcallosal interactions in visual cortex. Vis Neurosci 6:283-289. CrossRef Medline

Phillips DP, Irvine DR (1982) Properties of single neurons in the anterior auditory field (AAF) of cat cerebral cortex. Brain Res 248:237-244.

Pluto CP, Chiaia NL, Rhoades RW, Lane RD (2005) Reducing contralateral SI activity reveals hindlimb receptive fields in the SI forelimb-stump representation of neonatally amputated rats. J Neurophysiol 94:1727-1732. CrossRef Medline

Rauschecker JP, Tian B, Pons T, Mishkin M (1997) Serial and parallel processing in rhesus monkey auditory cortex. J Comp Neurol 382:89-103. CrossRef Medline

Ravizza RJ, Straw RB, Long PD (1976) Laminar origin of efferent projections from auditory cortex in the golden Syrian hamster. Brain Res 114: 497-500. CrossRef Medline

Reale RA, Imig TJ (1980) Tonotopic organization in auditory cortex of the cat. J Comp Neurol 192:265-291. CrossRef Medline

Rema V, Ebner FF (2003) Lesions of mature barrel field cortex interfere with sensory processing and plasticity in connected areas of the contralateral hemisphere. J Neurosci 23:10378-10387. Medline

Reinoso-Suàrez F (1961) Topographical atlas of the cat brain for experimental-physiological research [in German]. Darmstadt, Federal Republic of Germany: Merck.

Rochefort NL, Buzás P, Kisvárday ZF, Eysel UT, Milleret C (2007) Layout of transcallosal activity in cat visual cortex revealed by optical imaging. Neuroimage 36:804-821. CrossRef Medline

Rouiller EM, Simm GM, Villa AE, de Ribaupierre Y, de Ribaupierre F (1991) Auditory corticocortical interconnections in the cat: evidence for parallel and hierarchical arrangement of the auditory cortical areas. Exp Brain Res 86:483-505. Medline

Rüttgers K, Aschoff A, Friauf E (1990) Commissural connections between the auditory cortices of the rat. Brain Res 509:71-79. CrossRef Medline

Samara A, Tsangaris GT (2011) Brain asymmetry: both sides of the story. Expert Rev Proteomics 8:693-703. CrossRef Medline

Schmidt KE, Lomber SG, Innocenti GM (2010) Specificity of neuronal responses in primary visual cortex is modulated by interhemispheric corticocortical input. Cereb Cortex 20:2776-2786. CrossRef Medline

Schofield BR, Cant NB (1996) Origins and targets of commissural connections between the cochlear nuclei in guinea pigs. J Comp Neurol 375:128 146. CrossRef Medline

Silveira LC, Heywood CA, Cowey A (1989) Direct and transcallosal contribution to the cortical visual evoked response in rats. Behav Brain Res 31:291-294. CrossRef Medline

Thompson AM, Thompson GC (1991) Projections from the posteroventral cochlear nucleus to the superior olivary complex in guinea pig: light and EM observations with the PHA-L method. J Comp Neurol 311:495-508. CrossRef Medline

Weedman DL, Ryugo DK (1996) Pyramidal cells in primary auditory cortex project to cochlear nucleus in rat. Brain Res 706:97-102. CrossRef Medline

Winer JA (1992) The functional architecture of the medial geniculate body and primary auditory cortex. In: The mammalian auditory pathway: neuroanatomy (Webster DB, Popper AN, Fay RR, eds), pp 222-409. New York: Springer.

Yang XF, Kennedy BR, Lomber SG, Schmidt RE, Rothman SM (2006) Cooling produces minimal neuropathology in neocortex and hippocampus. Neurobiol Dis 23:637-643. CrossRef Medline

Yinon U (1994) Visual hemispheric dominance induced in split brain cats during development: a model of deficient interhemispheric transfer derived from physiological evidence in single visual cortex cells. Behav Brain Res 64:97-110. CrossRef Medline 